\title{
Fronteras exteriores, inmigración y refugio. La frustrante búsqueda de formas legales de acceso a Europa en el Derecho de la Unión: el incierto futuro del Visado Humanitario Europeo y del Marco Europeo de Reasentamiento
}

\author{
External Borders, Immigration and Refuge. The Frustrating Search \\ for Legal Forms of Access to Europe in the Law of the Union: \\ the Uncertain Future of the European Humanitarian Visa and the \\ European Resettlement Framework
}

\author{
M. ${ }^{\mathrm{a}}$ Dolores Bollo Arocena \\ Profesora Titular de D. ${ }^{\circ}$ Internacional Público \\ Universidad del País Vasco/Euskal Herriko Unibertsitatea \\ mariadolores.bollo@ehu.eus
}

Sumario: I. Introducción.-II. El tortuoso y aún incierto camino hacia el visado humanitario europeo. 1. El varapalo del TJUE al Visado Humanitario Europeo. 2. El intento de crear el visado humanitario mediante la reforma del Código Comunitario de Visados. 3. La iniciativa legislativa sobre Visado Humanitario Europeo aprobada por el Parlamento._-III. La propuesta de Reglamento por el que se establece el marco de reasentamiento de la Unión: un paso en la buena dirección pero claramente insuficiente. 1. La noción de reasentamiento y su puesta en práctica a escala universal y europea. 2. La propuesta de Reglamento por el que se establece un Marco de Reasentamiento de la Unión. 2.1 Objeto del Reglamento. 2.2. La definición de reasentamiento en la Propuesta de Reglamento. 2.3 Planes anuales y programas específicos de reasentamiento. 2.4 Ámbito subjetivo: criterios de admisibilidad e inadmisibilidad en los programas de reasentamiento. 2.6 Tipos de procedimiento: ordinario y acelerado. 2.6 Financiación.-IV. A modo de cierre.-V. Fuentes.

Resumen: En el último lustro las situaciones de conflicto armado existentes en distintos países africanos y de Oriente Medio ha traído consigo una afluencia de refugiados al viejo continente desconocida desde la segunda guerra mundial. Ante la imposibilidad de acceder a suelo europeo de forma legal, quienes huyen de la persecución y de la guerra se ven obligados a realizar un viaje que supone un alto coste para su vida, para su integridad física y mental y hasta para su dignidad. 
El propósito de este trabajo consiste en ahondar en dos iniciativas que se encuentran en marcha en este momento en el seno de la Unión y que, caso de resultar aprobadas, podrían permitir el acceso legal y seguro a Europa de un importante número de personas necesitadas de protección internacional. Estamos hablando del visado humanitario europeo y del proyecto de Reglamento por el que se establece el marco de reasentamiento de la Unión. Veremos si los Estados están a la altura de los principios y valores que presiden la organización de la que son miembros.

Palabras clave: protección internacional, refugio, visado humanitario europeo, reasentamiento.

Abstract. In the last five years armed conflict situations in different countries of the African continent and the Middle East has brought an influx of refugees to the old continent. This influx was not so high since the Second World War. As accessing legally to European soil is not possible, those refugees fleeing persecution and war are forced to make a trip that involves a high cost to their lives, their physical and mental integrity and, even their dignity.

The purpose of this work is to delve into two initiatives that are currently underway within the European Union and that, if approved, they could allow legal and secure access to Europe for a significant number of people requiring international protection. These initiatives are the European humanitarian visa and the Proposal for a Regulation establishing a Union Resettlement Framework. We will see if the States are up to the principles and values that preside over the organization of which they are members.

Keywords: international protection, refuge, european humanitarian visa, resettlement.

\section{Introducción ${ }^{1}$}

Habría que estar ciego y sordo y además tener una nula sensibilidad para ignorar la grave crisis en la que la Unión Europea se encuentra inmersa, no tanto por la llegada de importantes flujos de refugiados - también de migrantes económicos, es cierto - a suelo europeo como por la tremenda insolidaridad con la que sus Estados miembros están respondiendo ante esta dramática situación. No hay más que recordar los miles de personas que han perecido y siguen pereciendo en el Mediterráneo - en su desesperada huida de la persecución y de la guerra, también de la miseria más

${ }^{1}$ Este trabajo ha sido realizado en el marco del Proyecto de investigación «Los muros y el Derecho Internacional contemporáneo: implicaciones para la seguridad, la dignidad de la persona y el desarrollo sostenible» (DER2015-65486-R) financiado por el MINECO. 
absoluta - como consecuencia de una política europea más preocupada por la seguridad que por la garantía y el respeto de los derechos humanos; tampoco tenemos que olvidar la dificilísima situación en la que se encuentran una vez alcanzado el sueño europeo, sometidos en no pocas ocasiones a unas míseras y vergonzantes condiciones de vida, cuando no son directamente devueltos a supuestos países seguros. Y eso, por no hablar de la creciente corriente de xenofobia que ha renacido en distintos países de la Unión, haciéndonos recordar comportamientos que creíamos erradicados de nuestro entorno.

En ese contexto de la denominada crisis de los refugiados ${ }^{2}$, las instituciones comunitarias han emprendido desde hace ya algún tiempo un proceso de reforma del Sistema Europeo Común de Asilo (SECA), entramado normativo que regula, entre otras cosas, tanto el quién puede ser beneficiario de la protección internacional, como cuál es su estatuto, cuál es el procedimiento que ha de seguir para solicitarlo y cuál el estado responsable de estudiar cada solicitud. Sin embargo, para que todo ello se ponga en práctica la persona necesitada de protección internacional debe encontrarse en suelo europeo. Explícitamente se advierte en la Directiva $2013 / 32$ sobre procedimiento y en la 2013/33 sobre condiciones de acogida que sus disposiciones son aplicables solo a las personas que se encuentren en suelo europeo, no resultando de aplicación a las solicitudes realizadas en embajadas y consulados ${ }^{3}$. Y ese sigue siendo el tenor de las propuestas de reforma que están en este momento sobre la mesa ${ }^{4}$. Cabe plantear para qué sirve realmente este entramado normativo de tan dificilísima aplicación, teniendo en cuenta que quienes son sus últimos destinatarios, las personas necesitadas de protección internacional, no van a poder llegar a Europa sino de forma irregular. Y es que los diez países de los

2 Javier Andrés González Vega, «Mitos y mistificaciones: la Unión Europea y la protección internacional (a propósito de la crisis de los refugiados)», Revista de Derecho Comunitario Europeo, 56 (2017): 27-75.

${ }_{3}$ Directiva 2013/32/UE del Parlamento Europeo y del Consejo, de 26 de junio de 2013, sobre procedimientos comunes para la concesión o la retirada de la protección internacional (DO L 180, de 29 de junio de 2013), artículo 3.1 y 3.2. y Directiva 2013/33/UE del Parlamento Europeo y del Consejo, de 26 de junio de 2013, por la que se aprueban normas para la cogida de los solicitantes de protección internacional (DO L 180, de 29 de junio de 2013), artículos 3.1 y 3.2 .

${ }^{4}$ Propuesta de Directiva del Parlamento Europeo y del Consejo por la que se aprueban normas para la acogida de los solicitantes de protección internacional (texto refundido), 13 de julio de 2016, COM (2016) 465 final, COM (2016) 467 final, 2016/0222 (COD), artículo 3.2; Propuesta de Reglamento del Parlamento Europeo y del Consejo por el que se establece un procedimiento común en materia de protección internacional en la Unión y se deroga la Directiva 2013/32/UE, 13 de julio de 2016, COM (2016) 467 final, 2016/0224 (COD), artículo 2. 
que proceden el mayor número de refugiados ${ }^{5}$ son países a cuyos nacionales se les exige un visado para poder entrar en un Estado de la Unión, un visado que no pueden conseguir pues sus circunstancias hacen imposible que cumplan los requisitos exigidos para ello. Como consecuencia de ello, la realidad demuestra que el $90 \%$ de las personas a las que se les ha reconocido protección internacional han llegado de forma irregular. Ante este panorama, si queremos evitar el sufrimiento de seres humanos que lo han perdido todo, si de verdad lo queremos, es preciso articular mecanismos que posibiliten la llegada legal a Europa de quienes necesitan esa protección con el fin de evitar que arriesguen lo más preciado que tienen, su propia vida, y no solo eso sino su integridad física y mental, y hasta su propia dignidad, con el fin de alcanzar suelo europeo. De nada sirven los lamentos de los Estados miembros de la Unión y de sus instituciones si después de todos estos años de una crisis que, probablemente, ha llegado para quedarse, la respuesta se limite a declaraciones vacías de compromisos concretos. Desde luego no es una tarea fácil, pero es una obligación moral y una obligación jurídica para estar a la altura de los valores sobre los que se asienta la Unión, valores como la dignidad y el respeto de los derechos humanos - unos valores que deben tener un sentido y concretarse y guiar la aplicación del Derecho de la Unión ${ }^{6}-$, pero la realidad a día de hoy no podemos decir que sea ésa ${ }^{7}$.

Son diversas las herramientas que pueden utilizarse para posibilitar la llegada legal a Europa de las personas necesitadas de protección internacional, pero en este trabajo nos vamos a centrar en dos de ellas, pues existen propuestas en marcha en el seno de la Unión Europea en torno a ambas: por un lado, abordaremos el estudio del tan traído y llevado visado humanitario europeo, tomando como referencia las propuestas de reforma del Código de Visados, y por otro, nos referiremos al reasentamiento, tomando como referencia la Propuesta de Reglamento por el que se establece el Marco de Reasentamiento de la Unión.

${ }^{5}$ Según los datos ofrecidos por ACNUR estamos hablando de Siria, República Democrática del Congo, Sudán del Sur, Afganistán, Eritrea, Sudán, Somalia, República Centroafricana, Irak y Etiopía, UNHCR Projected 2019 Global Reasettlement needs, Ginebra, 25-26 junio 2017, 24. ${ }^{\text {a }}$ Consulta anual tripartita sobre reasentamiento, 60 .

${ }^{6}$ Conclusiones del abogado general Mengozzi en el asunto X y X c. Bélgica, C-638/16 PPU, EU:C:2017:93, apdo 165.

${ }^{7}$ Las cifras no engañan: la Unión Europea acoge al $8 \%$ de los refugiados del planeta a pesar de poseer el $23.8 \%$ del PIB mundial. Los países que verdaderamente acogen a una aplastante mayoría de refugiados son precisamente países en vías de desarrollo y lo hacen por este orden: Turquía, Uganda, Líbano, Irán, Etiopía, Jordania, Chad, Tanzania, Sudán y Kenia, UNHCR Projected 2019 Global Reasettlement needs, 61. 


\section{El tortuoso y aún incierto camino hacia el Visado Humanitario Europeo}

En los últimos tiempos el visado humanitario europeo ha recibido atención por parte de las principales instituciones de la UE: por el TJUE, en una sentencia ciertamente decepcionante dictada en marzo de 20178; por el Parlamento Europeo, primero proponiendo algunas enmiendas a ciertas disposiciones del Código Comunitario de Visados (en adelante CCV) al hilo de sendas propuestas de reforma del Reglamento (CE) n. ${ }^{\circ}$ 810/2009 presentadas por la Comisión, y, después, a través de una iniciativa legislativa aprobada en la Comisión LIBE, finalmente aprobada por el pleno del Parlamento el pasado 11 de diciembre de 2018; por el Consejo y la Comisión, quienes se han posicionado de forma beligerante a lo largo del tiempo en relación con las iniciativas del Parlamento. Veamos cuál ha sido el transcurrir del visado humanitario europeo y en qué punto nos encontramos en este momento.

\section{El varapalo del TJUE al Visado Humanitario Europeo}

Como es bien sabido y ha sido ya analizado por la doctrina ${ }^{9}$, el TJUE tuvo que resolver en marzo de 2017 una cuestión prejudicial en la que se le planteó si el vigente Derecho de la Unión imponía a los Estados miembros la obligación de conceder un visado de validez territorial limitada (en adelante VVTL) - regulado en el artículo 25 del CCV - en unas circunstancias como las que protagonizaba la familia siria, procedente de Alepo, que así lo solicitó ante el embajada de Bélgica en Beirut, explicitando que su intención era solicitar protección internacional una vez alcanzado suelo europeo ${ }^{10}$.

La respuesta del TJUE fue cuando menos decepcionante pues siguiendo un razonamiento que no compartimos $-\mathrm{y}$ opuesto al desarrollado por el Abogado General Paolo Mengozzi en sus conclusiones ${ }^{11}$ - afirmó que aunque las solicitudes de VVTL fueron presentadas formalmente sobre la base

${ }^{8}$ Sentencia del TJUE (Gran Sala) X y X c. Bélgica, C-638/16 PPU, EU:C:2017:173.

9 Silvia Morgades-Gil, «Humanitarian visas and EU Law: do States have limits to their discretionary power to issue humanitarian visas?, European Papers, Vol. 2, N. ${ }^{\circ} 3$ (2017): 1005-1016; Ángel Sánchez Legido, «El arriesgado acceso a la protección internacional en la Europa fortaleza: la batalla por el visado humanitario europeo», Revista de Derecho Comunitario Europeo, 57 (2017): 457-470; M.H. Zoeteweij-Turhan y A. Romano, «"X and X v. Belgium": the need for EU Legislation on humanitarian visa», Sui-generis (2017): 68 y ss. disponible en https://sui-generis.ch/article/view/sg.35/0.

10 Para ver el relato de los hechos, STJUE, cit., nota 8, apdos. 19 a 27.

${ }^{11}$ Conclusiones del abogado general Mengozzi en el asunto X y X c. Bélgica, C-638/16 PPU, EU:C:2017:93. 
del artículo 25 del CCV, no estaban comprendidas dentro de su ámbito de aplicación, añadiendo que el legislador de la Unión no había adoptado «hasta la fecha ningún acto sobre la base del artículo 79 TFUE, apartado 2, letra a), con respecto a las condiciones en las cuales los Estados miembros expedirán visados o permisos de residencia de larga duración a los nacionales de terceros países por razones humanitarias». Por lo tanto, concluyó que la situación controvertida no estaba regulada por el Derecho de la Unión, de ahí que no resultaran de aplicación las disposiciones de la Carta de Derechos Fundamentales ${ }^{12}$. En opinión del Tribunal, «las solicitudes controvertidas en el litigio principal solo están sujetas al derecho nacional» ${ }^{13}$. El TJUE cerró su razonamiento advirtiendo que si llegara a una conclusión contraria ello obligaría a permitir en la práctica que los nacionales de terceros países presentaran una solicitud de protección internacional en las representaciones de los Estados miembros situadas en el territorio de terceros Estados ${ }^{14}$.

A nuestro juicio, ello merece varias consideraciones. En primer lugar, el hecho de que se solicite un VVTL por motivos humanitarios, por ser víctima de persecución o de graves violaciones de derechos humanos, no transforma la naturaleza ni el objeto de la solicitud. Ni se convierte en una solicitud de protección internacional - pues eso es algo que en su caso vendría después - , ni tampoco en la solicitud de un visado de larga duración, puesto que el fundamento en virtud del cual la persona en cuestión podría llegar a disfrutar del derecho a permanecer en el territorio de un Estado miembro no sería el CCV sino la Directiva de procedimiento ${ }^{15}$.

En segundo lugar, por todo cuanto se acaba de señalar, la solicitud de un VVTL con la intención de solicitar protección internacional en el estado de destino, no quedaba fuera del ámbito de aplicación del CCV, pues, en el peor de los casos, podría tratarse de un supuesto de denegación del mismo de conformidad con lo dispuesto en el artículo $32 \mathrm{CCV}$. Sin embargo, tampoco consideramos que pueda hacerse esa lectura teniendo en cuenta que la citada disposición comienza diciendo que se denegará el visado si de dieran las circunstancias previstas en los apartados a) o b), «sin perjuicio de lo dispuesto en el artículo 25.1». Por lo tanto, aunque se diera cualquiera de tales situaciones, esto es, aunque, en particular, se pudieran tener dudas razonables sobre la intención del solicitante de abandonar el territorio del Estado miembro antes de expirar el plazo de vigencia del visado, incluso si así

12 STJUE, cit., nota 8, apdo. 45.

13 Ibid., apdo. 44 y 51.

14 Ibid., apdo. 49.

15 Conclusiones Abogado General, cit., nota 6, apdo. 50.Veáse Morgades Gil, «Humanitarian visas and EU Law: do States have limits to their discretionary power to issue humanitarian visas?, 1010 . 
fuera, el Estado debería expedirlo caso de existir razones humanitarias de peso, como era la situación de la familia siria ${ }^{16}$. Y es que, como recordó el Abogado General, una mera facultad concedida a un Estado miembro, recogida en un acto de derecho derivado de la Unión «puede transformarse en una verdadera obligación para ese mismo Estado miembro en aras a garantizar el respeto del artículo 4 de la Carta» ${ }^{17}$.

Por todo ello, y en la medida en que el Estado miembro aplica Derecho de la Unión, estaría obligado a respetar las obligaciones derivadas de la Carta de Derechos Fundamentales, por lo tanto, obligado a valorar si la denegación del visado podría suponer una violación de algún derecho recogido en la Carta, en particular los artículos 4 y 19 de la misma, en cuyo caso hubiera debido expedir el visado.

En tercer lugar, y atendiendo a criterio de puro sentido común, carece de toda justificación que dentro de la consideración «motivos humanitarios», que el Código no define, entre la asistencia médica al solicitante o a un familiar y que no entre el hecho de ser víctima de la persecución o de graves violaciones de derechos humanos. Como señaló el Abogado General, «se daría la paradoja de que cuanto más flagrantes fueran las razones humanitarias, menos cubiertas estarían por el ámbito de aplicación del artículo 25, apartado 1, letra a), del Código de visados» ${ }^{18}$.

Pero lo cierto es que el TJUE concluyó que la situación controvertida quedaba fuera del ámbito de aplicación del Derecho de la Unión - y en consecuencia fuera del ámbito de aplicación de la Carta- quedando cubierta única y exclusivamente por el derecho nacional. Pues bien, situados en el plano en el que nos coloca el TJUE, es necesario reflexionar en torno a si resulta de aplicación el principio de no devolución en el contexto de la actividad y las decisiones que adoptan embajadas y consulados en materia de expedición de visados y si, en un contexto como el presente en el caso objeto de estas reflexiones, resultaría de aplicación el CEDH, o, dicho de otro modo, como preguntó el órgano jurisdiccional remitente de la cuestión prejudicial, se trata de saber «si la aplicación de una política en materia de

${ }^{16}$ Compartimos la opinión del Abogado General cuando señaló que no tendría ningún sentido entender que podría extenderse un VVTL del artículo $25 \mathrm{CCV}$ a pesar de que la persona careciera de documento alguno de los exigidos en el aparatado 1.a) inciso i) de la disposición, incluso aunque se considere a esa persona una amenaza para el orden publico o la seguridad pública (inciso ii) y no quepa extender ese visado por el hecho que existan dudas razonables acerca de si el solicitante tiene verdaderamente la intención de abandonar el territorio de la Unión en el plazo exigido. Como muy gráficamente concluyó Paolo Mengozzi, «quien puede lo más puedo lo menos», Conclusiones Abogado General, cit., nota 6, apdo. 115.

${ }^{17}$ Sentencia del TJUE (Gran Sala) N.S y otros, C-411/10 y C-493/10, ECLI:EU:C:2011:865, apdos. 94-98.

18 Conclusiones Abogado General, cit., nota 6, apdo. 130. 
visados y la toma de decisiones sobre solicitudes de visado pueden calificarse de ejercicio de una jurisdicción efectiva» ${ }^{19}$.

Son diversos los asuntos y de distinta índole en los que la desaparecida Comisión de Derechos Humanos puso de manifiesto que la responsabilidad del Estado puede verse comprometida por las acciones u omisiones de los funcionarios del Estado, incluidos los agentes diplomáticos y consulares. Así, por ejemplo, en 1992 la Comisión de Derechos Humanos tuvo ocasión de abordar la situación creada como consecuencia de medidas adoptadas por el embajador danés en la antigua República Democrática Alemana consistente en entregar a la policía de ese país a 17 personas que habían buscado refugio en la embajada de Dinamarca en Berlín oriental. Pues bien, con independencia de la posición que mantuviera finalmente sobre el fondo del asunto, la Comisión afirmó que «il resort d'une jurisprudence constante de la Commission que les fonctionnaires d'un Etat y compris les agents diplomatiques ou consulaires attirent le personnes et les biens sous juridiction de cet Etat dans la mesure ou ils exercent leur autorité sur ces personnes ou sur ces biens. Des lors que ces derniers se trouvent affectés par les actes ou omissions des fonctionnaires, la responsabilité de l'Etat est engagée (...) Il s'ensuit qu'en l'espece la Commission est convaincue que les mesures litigieuses prises par l'ambassadeur danois afectaient des personnes relevant de la juridiction des autorités danoises au sens de l'article $1 \gg^{20}$.

En esta línea, a nuestro juicio, de llegar un contexto fáctico similar al del caso X. y X. c. Bélgica, no ante el TJUE sino al TEDH, nos aventuramos a afirmar que la denegación de un visado con el fin de alcanzar territorio europeo podría y a nuestro juicio debería ser calificada por el TEDH como una violación del artículo 3 del CEDH, porque la adopción de tal decisión por parte de los funcionarios del Estado, como lo son los agentes diplomáticos y consulares en el exterior, en el ejercicio de su jurisdicción, colocaría a la familia ante el riesgo de sufrir una violación del derecho a no ser sometido a tortura, tratos inhumanos o degradantes en el caso de tener que vol-

19 Conclusiones Abogado General, cit., nota 6, apdo. 36. Abordando de manera general esta cuestión, J. Abrisketa Uriarte, «La dimensión externa del derecho de la Unión Europea en materia de refugio y asilo: un examen desde la perspectiva del principio de non-refoulement», Revista de Derecho Comunitario Europeo, 56 (2017): 145-151. Realizando un estudio específico sobre el particular, Sánchez Legido, Externalización de controles..., 100-106.

${ }^{20}$ Comisión de Derechos Humanos, M. c. Dinamarca, Decisión sobre admisibilidad, 14 de octubre de 1992. La cursiva es nuestra. En una línea similar, X c. República Federal Alemana, Decisión 25 septiembre de 1965; X c. Reino Unido, Decisión 17 de diciembre de 1977. En la doctrina, sobre este particular, Kees Wouters, International legal standards for the protection from refoulement: a legal analysis of the prohibitions on refoulement contained in the Refugee Convention, the European Convention on Human Rights, The International Covenant on Civil and Political Rights and the Convention against Torture, (2009): 218. 
ver a Siria, sin que la permanencia en Líbano pudiera ser considerada como una opción dada la situación de la familia protagonista del asunto X. y X.c. Bélgica. Y es que, como recordó el Abogado General, desde mayo de 2015 el gobierno de Líbano notificó a ACNUR que debía suspender el registro de nuevos refugiados sirios. Los no registrados quedaban privados de la posibilidad de conseguir el estatuto de solicitante de asilo en ese país y corrían el riesgo de ser detenidos por estancia ilegal, siendo su situación de precariedad absoluta: «alojados con frecuencia en refugios muy rudimentarios como garajes o meras tiendas de campaña, en un país en el que no existe ningún campo oficial, y cuyo acceso a la comida y al agua, a los cuidados de salud y a la educación es extremadamente difícil si no precario» ${ }^{21}$. Y todo esto agravado en el caso concreto, por tratarse de personas que profesaban la religión cristiana, lo que se traducía en el sometimiento a «ostracismo, intimidación y actos graves de violencia contra esa minoría religiosa, tanto en el Líbano como en otros países limítrofes como Jordania, incluso dentro de los propios campos de refugiados» ${ }^{22}$.

Como ha puesto ya de relieve Sánchez Legido, «las funciones de control migratorio que desempeñan embajadas y oficinas consulares constituyen un ejemplo de libro en el que concurre jurisdicción de iure, pues se encuentran amparadas en el Derecho internacional, y jurisdicción de facto, pues del ejercicio de las prerrogativas públicas que tales funciones comportan pueden derivarse importantes consecuencias para los más esenciales derechos de la persona» ${ }^{23}$. Por tanto, a nuestro juicio, el principio de no devolución también debe resultar aplicable en embajadas y consulados en el marco de la actividad administrativa consistente en la expedición de visados, solicitados por los interesados con el fin de huir de la persecución y de la guerra. La denegación del visado por parte de las autoridades consulares belgas, denegación realizada en el ejercicio de sus funciones, en un contexto como el X. y X.c. Bélgica, colocó a la familia en pleno ante riesgo claro y objetivo de ser sometidos a torturas, tratos inhumanos o degradantes, en violación del artículo 3 del $\mathrm{CEDH}^{24}$.

${ }^{21}$ Conclusiones Abogado General, cit., nota 6, apdo. 154 (citas omitidas).

${ }^{22}$ Conclusiones Abogado General, cit., nota 6, apdo. 154 in fine.

23 Sánchez Legido, Externalización de controles..., 104 (citas omitidas).

${ }^{24}$ En este sentido Wouters, International legal standards..., 218. A nuestro juicio, esta interpretación no hace sino seguir la estela y mantener la congruencia con lo dictaminado por el TEDH en el caso Hirsi Jamaa y otros c. Italia, STEDH de 23 febrero de 2012. Para ver un comentario a la misma, M. ${ }^{a}$ Dolores Bollo Arocena, «Push back, expulsiones colectivas y principio de non refoulement. Algunas reflexiones a propósito de la sentencia dictada por la Gran Sala del Tribunal Europeo de Derechos Humanos en el caso Hirsi Jamma y otros c. Italia (2012)», El Derecho Internacional en el mundo multipolar del siglo XXI: Obra Homenaje al Prof. Luis Ignacio Sánchez Rodríguez (Coord. S. Torres Bernárdez) (2013): 647-666. 


\section{El intento de crear el visado humanitario mediante la reforma del Código Comunitario de Visados}

Aunque no compartimos la doctrina que se extrae de la sentencia dictada por el TJUE en el asunto X y X. c. Bélgica, lo cierto es que la interpretación realizada y a la que nos acabamos de referir, pondría de manifiesto la existencia de una laguna jurídica en el Derecho de la Unión puesto que, dejando a un lado el mecanismo de reasentamiento al que más adelante nos referiremos - y que también tiene unas limitaciones considerables - no existen procedimientos específicos para la admisión en el territorio europeo de personas que buscan protección internacional, por lo que se les condena una y otra vez a recurrir a vías irregulares e inseguras de acceso y se alimenta el negocio de las mafias que viven, precisamente, de esa laguna jurídica. Las tragedias vividas en el Mediterráneo desde el inicio de la crisis han hecho que el Parlamento Europeo venga reclamando de forma reiterada y a través de distintas Resoluciones, la necesidad de articular vías legales de acceso a Europa para las personas necesitadas de protección internacional. A título meramente ilustrativo cabe mencionar la Resolución sobre la situación en el mar Mediterráneo y la necesidad de un enfoque integral de la Unión sobre la migración, adoptada el 12 de abril de 2016, en la que el Parlamento hizo un llamamiento para que las personas que tratan de obtener protección internacional pudieran solicitar un visado humanitario directamente ante cualquier consulado o embajada de los Estados Miembros, de tal forma que una vez concedido debía permitir a su titular entrar en el territorio del Estado miembro que lo hubiera emitido con la finalidad exclusiva de solicitar allí protección internacional ${ }^{25}$. La resolución advertía de la necesidad de modificar el CCV «para incluir disposiciones comunes más específicas relativas a los visados humanitarios» ${ }^{26}$.

Ya el 1 de abril de 2014 la Comisión había presentado una propuesta de Reglamento relativo al Código sobre visados de la Unión (Código de visados), una propuesta centrada en estimular el crecimiento en la UE, dado el impacto económico de la política de visados en el conjunto de la economía de la Unión, en particular en el ámbito del turismo ${ }^{27}$. Dado que esa era la

25 Resolución del Parlamento Europeo, de 12 de abril de 2016, sobre la situación en el mar Mediterráneo y necesidad de un enfoque integral de la Unión sobre la migración (2015/2095 (INI)), apdo. 27.

${ }^{26}$ Ibidem. Este aspecto ya había sido destacado en los mismos términos en la Resolución del Parlamento Europeo, de 10 de septiembre de 2015, sobre la migración y los refugiados (2015/2833(RSP), apdo. 13.

27 Propuesta de Reglamento del Parlamento Europeo y del Consejo relativo al Código sobre visados de la Unión (Código de visados) (refundición), 1 de abril de 2014, COM(2014) 164 final, 2014/0094 (COD), Motivación y objetivos de la propuesta, p. 0. 
filosofía que estaba detrás de la reforma, la propuesta mantenía inalterado el artículo 25 del aún hoy vigente Reglamento (artículo 22 de la propuesta presentada) relativo al VVTL. Pues bien, siguiendo la línea que venía marcando el Parlamento Europeo y a la que nos acabamos de referir, la Comisión de Libertades Civiles, Justicia y Asuntos de Interior (Comisión LIBE) aprobó una serie de propuestas de enmienda al Código de visados, precisamente con la idea de crear sobre él el visado humanitario europeo ${ }^{28}$.

Por un lado, la Comisión LIBE propuso varias enmiendas destinadas a reforzar las disposiciones vigentes con el fin de interpretarlas de un modo menos rígido, particularmente los aspectos relacionados con «motivos humanitarios» y «obligaciones internacionales» ${ }^{29}$. Así, la propuesta de artículo 17.4 señalaba que se consideraría admisible (frente al «podrá considerarse admisible» del vigente reglamento) una solicitud de visado que no cumpla los requisitos fijados en el artículo 17.1 «si el Estado miembro de que se trate lo estima necesario por razones humanitarias o de interés nacional» y añadía la enmienda del Parlamento «o debido a obligaciones internacionales» ${ }^{30}$.

Por otro lado, la Comisión LIBE propuso incluir en un nuevo considerando, el 26 bis, el deber de prever la posibilidad de solicitar un visado humanitario ${ }^{31}$, algo que después se plasmaba en la propuesta de articulado: por un lado, incluía una apostilla en el apartado 22.1 a) ${ }^{32}$ (esto es, el vigente 25.1.a)), en el que se explicitaba que se expedirá un VVTL cuando el Estado miembro lo considere necesario por razones humanitarias o interés nacional o debido a obligaciones internacionales «en particular cuando sea necesario para garantizar la protección internacional de la persona interesada de conformidad con la Convención de las Naciones Unidas sobre el Estatuto de los Refugiados de 1951 u otros instrumentos pertinentes de la Unión o internacionales» ${ }^{33}$. Pero, además, se propuso un nuevo artículo, el 22.5 bis, en virtud del cual las personas que requirieran protección internacio-

${ }^{28}$ Las enmiendas fueron aprobadas el 16 de marzo de 2016 con el voto favorable de 46 de sus miembros, 4 votos en contra y 7 abstenciones, Informe de la Comisión LIBE sobre Informe sobre la propuesta de Reglamento del Parlamento Europeo y del Consejo relativo al Código sobre visados de la Unión (Código de visados) (versión refundida), Comisión de Libertades Civiles, Justicia y Asuntos de Interior. Ponente: Juan Fernando López Aguilar, 22 de abril de 2016 (Ref. A8-0145/2016), 126. (en adelante Informe de la Comisión Libe 2016 sobre el Código de visados).

29 Argumentos sintetizados en el Documento de trabajo sobre visados humanitarios, Comisión LIBE, Ponente: Juan Fernando López Aguilar, 5 de abril de 2018 (PE619.272v02-00), 2.

${ }^{30}$ Informe de la Comisión LIBE 2016 sobre el Código de visados, enmienda 73.

31 Ibid., Enmienda 15.

32 Ibid., Enmienda 94.

33 Ibid., Enmienda 95, en la que se pretendía «aclarar que las "obligaciones internacionales" podrían incluir la concesión de protección a un nacional de un tercer Estado». 
nal podrían solicitar un visado humanitario europeo directamente ante cualquier consulado o embajada de los Estados miembros. Una vez concedido, tras la correspondiente evaluación, su titular podría entrar en el territorio del Estado miembro que se lo hubiera expedido con la «finalidad exclusiva» de solicitar allí protección internacional conforme a lo dispuesto en el derecho de la Unión ${ }^{34}$.

Sin embargo, las propuestas del Parlamento fueron rechazadas de pleno tanto por parte del Consejo como de la Comisión, esgrimiendo argumentos de distinto calado: desde la consideración de que el Código de visados no era lugar adecuado para introducir el visado humanitario, pues se refiere a visados de corta duración, pasando por la afirmación de la existencia de otras vías legales de acceso a los Estados miembros, como el reasentamiento, o el temor de sobrecargar a los consulados ${ }^{35}$.Tras meses de bloqueo en los que el Consejo se negó a seguir negociando el Código de visados si no se retiraban las enmiendas propuestas, el equipo negociador del Parlamento procedió a retirarlas. El bloqueo continuó a pesar de todo, de ahí que la Comisión anunciara en abril de 2018 la retirada de la propuesta de Reglamento relativo al Código de visados que había presentado en $2014^{36}$.

La Comisión ha vuelto a presentar en marzo de 2018 una nueva Propuesta por la que se modificaría el Reglamento (CE) n. ${ }^{\circ} 810 / 2009$ por el que se establece un Código Comunitario sobre visados (Código de visados) ${ }^{37}$, puesto que al margen de los desacuerdos a los que nos acabamos de referir y que llevaron a retirar la propuesta de 2014, la Comisión ha entendido que el enfoque de esa propuesta no es el adecuado en el momento actual a la vista del incremento de los desafíos migratorios y en materia de seguridad, aunque reconoce que la mayoría de los solicitantes de visado no solo no plantean riesgos de esa naturaleza sino que aportan importantes beneficios a la Unión. Probablemente ante la duda de que sea atendida por parte de la Comisión el informe de iniciativa legislativa del

${ }^{34}$ Ibidem. Por su parte, la enmienda 96, que incluía una propuesta de un nuevo artículo 22 bis señalaba: «Al conceder un visado humanitario o de protección internacional, los Estados Miembros fijarán excepciones a la duración de 90 días en un período de 180 días para una duración de un año, renovable, en función del análisis de la situación del país de origen o residencia del nacional de un tercer país, prestando especial atención a las circunstancias de las personas que solicitan protección internacional». Todo ello en Informe de la Comisión LIBE 2016 sobre el Código de visados.

35 Argumentos sintetizados en el Documento de trabajo sobre visados humanitarios, 3.

${ }^{36}$ Retirada de la propuestas de la Comisión (2018/C 233/05), C 233/7 DOUE 4 de julio de 2018 .

37 Propuesta de Reglamento del Parlamento Europeo y del Consejo por el que se modifica el Reglamento (CE) n. ${ }^{\circ} 810 / 2009$ por el que se establece un Código comunitario sobre visados (Código de visados), COM (2018) 252 final, 2018/0061 (COD), 14 de marzo de 2018. 
propio Parlamento para la creación de un visado humanitario europeo, a la que nos vamos a referir de forma inmediata, el Parlamento ha decidido de nuevo plantear algunas enmiendas a la nueva propuesta de reforma del Código de visados. El pasado 11 de diciembre de 2018 el Parlamento Europeo aprobó un total de 78 enmiendas, que habían sido previamente aprobadas en el seno de la Comisión $\mathrm{LIBE}^{38}$, algunas de ellas referidas a la cuestión que nos ocupa en este lugar ${ }^{39}$.

Por un lado, la enmienda 4 supondría la inclusión de un nuevo considerando, el 2 bis, en el que se recuerda que pese a los esfuerzos realizados aún no existe un auténtico derecho de asilo armonizado ni «un marco jurídico para los visados humanitarios europeos, que son competencia exclusiva de los Estados». No obstante, se reconoce explícitamente que los consulados deben poder conceder visados con el fin de que las personas necesitadas de protección internacional puedan acceder a suelo europeo de forma segura, utilizando para ello las excepciones que el propio Reglamento reconoce, por razones humanitarias o para respetar las obligaciones internacionales, en particular la Convención de 1951 sobre el Estatuto de los Refugiados. Siguiendo la misma línea, la enmienda 5, que supondría la inclusión del considerando 4 bis, recuerda que la expedición de un visado a una persona que busca protección constituye un medio para permitirle acceder al territorio de los Estados miembros de una manera segura. Por lo tanto, «cuando se examine la competencia territorial consular, la admisibilidad de una solicitud de visado o la posibilidad de expedir un visado de validez territorial limitada, los consulados habrán de prestar especial atención a las personas que buscan protección». Para dichas personas, señala con rotundidad, «los Estados miembros deberán recurrir a las exenciones por motivos humanitarios o por obligaciones internacionales previstas en el presente Reglamento». Ya en el texto del articulado, la propuesta de enmienda 44 supone una modificación del artículo 19.4 del CCV, de tal forma que se añade el cumplimiento de las obligaciones internaciones como causa para considerar admisible una solicitud de visado, aún no cumpliendo los requisitos fi-

38 Informe sobre la propuesta de Reglamento del Parlamento Europeo y del Consejo por el que se modifica el Reglamento (CE) n. ${ }^{\circ}$ 810/2009 por el que se establece un Código comunitario sobre visados (Código de visados), Comisión de Libertades Civiles, Justicia y Asuntos de Interior. Ponente: Juan Fernando López Aguilar, 6 de diciembre de 2018 (Ref. A80434/2018).

${ }^{39}$ Las enmiendas fueron aprobadas con el apoyo de una importante mayoría de europarlamentarios: 401 votos a favor, 222 en contra y 40 abstenciones. Enmiendas aprobadas por el Parlamento Europeo el 11 de diciembre de 2018 sobre la propuesta de Reglamento del Parlamento Europeo y del Consejo por el que se modifica el Reglamento (CE) n. ${ }^{\circ} 810 / 2009$ por el que se establece un Código comunitario sobre visados (Código de visados) COM (2018) 252C8-0114/2018-2018/0061 (COD), P8_TA-PROV(2018)0495. 
jados en el apartado 1 del artículo 19. Por lo demás, tanto en la propuesta de inclusión de nuevos considerandos ( 2 bis, 6 bis, 13 bis, 17 bis, 27 ter $)^{40}$, como en la propuesta de inclusión del nuevo artículo 1.1.bis y de enmienda del artículo 39.1 del texto en vigor ${ }^{41}$, el Parlamento recalca que tanto el Reglamento en sí mismo, como los Estados miembros en el momento de aplicarlo, deben respetar la CDFUE, la Convención de 1951 sobre el Estatuto de Refugiados, el CEDH y el resto de tratados internacionales particularmente significativos en materia de derechos humanos.

Veremos qué camino sigue en los próximos meses el Reglamento sobre el Código de visados, aunque muchos nos tememos que sigue sin existir la voluntad política necesaria para que resulte aprobada en los términos propuestos por el Parlamento.

\section{La iniciativa legislativa sobre Visado Humanitario Europeo aprobada por el Parlamento}

Como ya se ha señalado, las propuestas de enmienda al CCV realizadas por el Parlamento fueron rechazadas, considerando que ese no era el lugar para regular el visado humanitario europeo. Por ello, en diciembre de 2017 la Comisión LIBE obtuvo la autorización para elaborar un informe de iniciativa legislativa sobre la base de los artículos 225 TFUE y 46 del Reglamento interno del Parlamento, con el propósito de solicitar a la Comisión que presentara una propuesta legislativa para la creación de un visado humanitario europeo en un instrumento independiente, a más tardar en marzo de 2019, dada la urgencia de la cuestión y los amplios debates que ya se habían producido sobre el particular.

El informe preparado por el ponente, el Sr. López Aguilar, fue remitido al Pleno del Parlamento Europeo donde, tras el correspondiente debate, el proyecto de informe fue sometido a votación el día 14 de noviembre de 2018, quedándose a escasos 25 votos de ser aprobado por el pleno. Sin bien el ponente, pretendió que se sometiera de nuevo a votación al día siguiente, por entender que se había producido un error en el sistema de votación - pues de las exposiciones orales de los distintos grupos parecía desprenderse la existencia de una mayoría de europarlamentarios que apoyaban la iniciativa - la presidencia entendió que no se había producido error alguno y que esa era la voluntad real del Parlamento.

40 Propuestas de enmiendas 3, 10, 17, 20 y 22 aprobadas por el Parlamento Europeo (P8_ TA-PROV(2018)0495), referidas a la inclusión de los nuevos considerandos mencionados.

${ }^{41}$ Propuesta de enmiendas 24 y 68 aprobadas por el Parlamento Europeo (P8_TAPROV(2018)0495). 
En esas circunstancias, la Comisión LIBE volvió a estudiar el proyecto de informe presentado por el ponente, no sin que algunos de sus miembros se mostraran extremadamente críticos con el hecho de que se sometiera de nuevo a examen, pues entendieron que dado que había sido rechazado pocos días antes, «la realización de una nueva votación en tan poco tiempo y sin haber realizado ningún otro análisis o modificación sustancial en el texto» mostraría «una falta de respeto preocupante por los principios básicos de la democracia» ${ }^{42}$. No obstante, finalmente, y tras la aceptación de una enmienda ${ }^{43}$, el 3 de diciembre de 2018 fue aprobado el proyecto por 37 votos a favor, 10 en contra y 3 abstenciones, tras lo cual fue sometida a nueva votación ante el Pleno del Parlamento Europeo el 11 de diciembre, y esta vez, sí, la resolución fue aprobada ${ }^{44}$. Veremos si la Comisión recoge el guante tendido por el Parlamento europeo aunque mucho nos tememos que van a ser muchas las dificultades que surjan en el camino, algunas de las cuales ya se pusieron de manifiesto en el seno de la propia Comisión LIBE, no tanto por problemas de índole jurídico sino por la inexistencia de una voluntad política real de permitir la llegada ordenada de solicitantes de protección internacional a la Unión.

$\mathrm{Si}$ bien el primer informe de iniciativa legislativa aprobado por la Comisión LIBE, al referirse a la fundamentación legal para su adopción, mencionaba el artículo 77.2 a) TFUE — en el que se establece que el Parlamento Europeo y el Consejo adoptarán medidas relativas «a la política común de visados y otros permisos de residencia de corta duración»- en relación con el artículo 78.2 g) TFUE — referido a la asociación y a la cooperación con terceros países para gestionar los flujos de personas que solicitan asilo o una protección subsidiaria o temporal» como modo de desarrollar una política común en materia de asilo, protección subsidiaria y protección temporal destinada a ofrecer un estatuto apropiado a todo nacional de un tercer país que necesite protección internacional y garantizar el respeto del principio de no devolución, o una protección subsidiaria o temporal»-, la propuesta sometida y aprobada por el Parlamento omite la referencia al artículo 78 TFUE.

42 Enmienda 2 (Harald Vilimsky, Gilles Lebreton y Nicolas Bay), Informe de la Comisión LIBE 2018 sobre Código de visados. En la misma línea, enmienda 20 (Branislav Skirpek).

${ }^{43}$ En el seno de la Comisión LIBE el eurodiputado Jeroen Lenaers propuso incluir en el punto 3 de la resolución que «la decisión de expedir visados humanitarios europeos debe seguir constituyendo una competencia exclusiva de los Estados Miembros» y así se aprobó en el seno de la Comisión y en el seno del Parlamento Europeo. Enmienda 28, Informe de la Comisión LIBE 2018 sobre Código de visados.

${ }^{44}$ Carta abierta a los miembros del Parlamento Europeo apoyada por un importante número de reputados miembros de la Academia, especialistas en la materia en Open Letter to MEPs on Humanitarian Visas disponible en https://www.bartstaes.be/assets/data/files/Documents/VisasOpenLetter.pdf 
La propuesta del Parlamento Europeo no pretende introducir la evaluación extraterritorial de las solicitudes de protección internacional, sino un procedimiento mediante el cual el nacional de un tercer país pueda solicitar el visado humanitario con el fin de acceder al territorio de la Unión y presentar la solicitud de protección internacional en el Estado de destino. Para ello el solicitante debe demostrar, prima facie, que se encuentra en una situación cubierta por la denominada protección internacional y que su solicitud no está manifiestamente mal fundada, siempre teniendo en cuenta que una persona que huye de la persecución o de la guerra es probable que no pueda documentar todo cuanto señala de manera absolutamente detallada.

Cerrada la vía del visado de VVTL del art. 25 del vigente CCV por parte del TJUE y mientras no exista una reforma del citado Código, es evidente que el Derecho de la Unión presenta una laguna jurídica puesto que, si bien se reconoce el derecho de asilo no se prevén procedimientos específicos para permitir la llegada, por vías legales y seguras, a personas necesitadas de protección. Esa laguna a escala de la Unión no impide a los Estados miembros articular sus propios sistemas para permitir la entrada legal de estas personas en sus respectivos territorios, circunstancia que siendo, obviamente, positiva podría afectar a la aplicación uniforme de los Reglamentos n. ${ }^{\circ} 810 / 2009$ por el que se establece el CCV y 2016/399 por el que se establece el Código de Fronteras Schengen ${ }^{45}$.

La aprobación del Reglamento supondría un avance notable desde un punto de vista humano: objetivamente, serían muchas menos las personas que fallecerían en el camino y muchas menos aún las que sufrirían física y mentalmente el coste que supone un viaje en las condiciones en las que lo realizan. Pero incluso desde un punto de vista estrictamente económico, la creación de una vía como la que se propone permitiría reorganizar los recursos de otro modo, tanto de la UE como de los Estados miembros, puesto que muy probablemente habría que destinar menos fondos a la protección de las fronteras exteriores, a las tareas de salvamento y socorro, a la gestión de los flujos descontrolados de personas y a sufragar el gasto que supone el retorno de quienes no tienen derecho a permanecer en la Unión. Evidentemente habrá que seguir destinando fondos a esos fines, porque seguirán llegando personas de forma irregular, pero en un número considerablemente inferior.

El visado humanitario europeo iría destinado a los nacionales de terceros Estados que necesitan protección internacional, pero que al mismo necesitan de un visado para acceder al territorio de la Unión de conformidad

45 Anexo a la Resolución del Parlamento Europeo, de 11 de diciembre de 2018, con recomendaciones destinadas a la Comisión sobre los visados humanitarios (2018/227 (INL)), P8_TA-PROV(2018)0494, apdo. 3. Justificación. 
con lo dispuesto en el Reglamento (CE) 539/2001. Y es que, como apuntábamos anteriormente, los diez países desde los que proviene el mayor número de refugiados son países cuyos nacionales necesitan de visado para acceder al territorio de la Unión ${ }^{46}$.

La propuesta presentada por el Parlamento concibe el visado humanitario europeo como un visado de validez territorial limitada que podrá solicitarse - ya sea personalmente o por vía electrónica o por escrito - ante cualquier consulado o embajada - descartando la propuesta de algún miembro de la Comisión LIBE en el sentido de limitar, por parte de los Estados, las embajadas y consulados ante los que se podría solicitar el visado- mediante un procedimiento similar, en la medida de lo posible, al previsto para la expedición de visados de corta duración ${ }^{47}$. Como es lógico, el solicitante deberá ser entrevistado con el fin de valorar adecuadamente si se trata prima facie de una solicitud bien fundada o no. Para ello se prevé no solo la opción de la entrevista personal en directo, sino también la realización de entrevistas a través de los medios de comunicación audiovisual actualmente disponibles, cuando así lo exijan motivos de seguridad o de otra naturaleza. Las entrevistas, naturalmente, habrán de ser realizadas por personas con experiencia y conocimientos en materia de protección internacional - que no tienen porqué encontrarse en el terreno sino en los Estados miembros - , siempre teniendo en mente que es una tramitación de un visado y no una tramitación de una solicitud de protección internacional. Se trata de comprobar que existen motivos fundados para creer que la persona está expuesta o corre el riesgo de estar expuesta a la persecución ${ }^{48}$.

46 Otra opción, sencilla desde el punto de vista de articulación jurídica, pero más dificultosa desde un punto de vista político por razones de seguridad, consistiría en eliminar a esos Estados de la lista que figura en el anexo al Reglamento (CE) 539/2001 o al menos suspender temporalmente la exigencia del visado a los nacionales de esos Estados. Sin embargo, mucho nos tememos que esa opción no encontrará los apoyos necesarios para ser aprobada. Cfr. en este sentido Humanitarian Visas. European Added Value Assessment accompanying the European Parliament's legislative own-initiative report (Rapporteur: Juan Fernando López Aguilar) (octubre 2018), 86-90, disponible en https://publications.europa.eu/en/publicationdetail/-/publication/a3b57ef6-d66d-11e8-9424-01aa75ed71a1/language-en/format-PDF.

${ }^{47}$ El Parlamento ha propuesto la creación de un impreso de solicitud específico en el que se haga constar la información sobre la identidad del solicitante, los motivos por los que teme la persecución junto con la documentación que pueda servir para demostrar la necesidad del visado solicitado, Anexo a la Resolución del Parlamento Europeo, de 11 de diciembre de 2018, con recomendaciones destinadas a la Comisión sobre los visados humanitarios (2018/227 (INL)), P8_TA-PROV(2018)0494.

48 Anexo a la Resolución del Parlamento Europeo, de 11 de diciembre de 2018, con recomendaciones destinadas a la Comisión sobre los visados humanitarios (2018/227 (INL)), P8_ TA-PROV(2018)0494 y el Informe previo con recomendaciones destinadas a la Comisión sobre visados humanitarios aprobado por la Comisión LIBE, siendo ponente Juan Fernando López Aguilar, de 4 de diciembre de 2018, A8-0423/2018. 
La respuesta a la solicitud de visado, según la propuesta del Parlamento europeo, debe ofrecerse en el plazo de 15 días naturales desde la presentación de la solicitud - y no de 30 días como propusieron algunos miembros de la Comisión LIBE ${ }^{49}$ - , tiempo que más que suficiente teniendo en cuenta la situación en la que se encuentran quienes solicitan un visado humanitario. La decisión habrá de comunicarse por escrito, de manera personalizada y motivada, en un idioma que la persona solicitante pueda comprender, con el fin de que pueda recurrir de una forma similar a la que hoy se reconoce a quien se le deniega un visado de corta duración o a quien se le deniega la entrada en frontera.

Frente a la sugerencia del algún miembro de la Comisión LIBE de que fueran los propios Estados quienes financiaran los costes derivados del visado humanitario ${ }^{50}$, el Parlamento ha propuesto que los Estados miembros reciban apoyo financiero del Fondo Europeo para la Gestión Integrada de Fronteras y que el Estado miembro que expida un visado humanitario reciba la misma compensación que recibe el Estado que reasienta a un refugiado, mediante el apoyo del Fondo de Asilo, Migración e Integración, tal y como luego tendremos ocasión de analizar. Es la manifestación lógica del principio de solidaridad y de reparto equitativo de la responsabilidad, también en el aspecto financiero ${ }^{51}$.

La aprobación de un Reglamento como el propuesto permitiría a la UE recuperar la credibilidad perdida en estos años, pues supondría afrontar la gestión de los flujos de refugiados y migrantes con pleno sometimiento a los valores que la presiden, de respeto a la dignidad y a los derechos humanos. Sin embargo, es necesario agilizar al máximo su aprobación y su puesta en práctica, frente a la propuesta del propio Parlamento de establecer un período de transición de 2 años antes de empezar a aplicar la nueva norma desde que resulte aprobada, lo que nos podría llevar, siendo optimistas, hasta finales de 2021. La situación de las personas por las que se diseña una norma como la que crea el visado humanitario europeo no puede esperar 3 años. Por ese motivo, consideramos más acertado que ese período de transición de 2 años desaparezca y que, si acaso, se acepte la propuesta

49 Enmienda 34 presentada por Jeroen Lenaers, Informe de la Comisión LIBE 2018 sobre Código de visados.

${ }^{50}$ Enmienda 30 propuesta por Gerard Batten y Jörg Meuthen pretendía que se incluyera en el punto 6 de la Resolución un matiz en virtud del cual los Estados que deseen expedir visados humanitarios «deberán ser responsables de todas repercusiones financieras que se deriven de la autorización de entrada de personas en el territorio del Estado miembro de que se trate», Informe de la Comisión LIBE 2018 sobre Código de visados.

51 Anexo a la Resolución del Parlamento Europeo, de 11 de diciembre de 2018, con recomendaciones destinadas a la Comisión sobre los visados humanitarios (2018/227 (INL)), P8_TA-PROV(2018)0494. 
de crear regiones piloto en las que durante ese período podría aplicarse la nueva norma, a fin de contar con un entorno controlado en el que poner a prueba la idoneidad y la eficacia de la misma, transcurrido el cual el Reglamento desplegaría plenos efectos a lo largo y ancho del planeta, allí donde sea necesaria su puesta en práctica.

\section{La propuesta de Reglamento por el que se establece el Marco de Reasentamiento de la Unión, un paso en la buena dirección pero claramente insuficiente}

\section{La noción de reasentamiento y su puesta en práctica a escala universal y europea}

Decíamos al inicio que nuestro propósito en este trabajo consiste en explorar dos vías que podrían permitir el acceso legal de las personas necesitadas de protección internacional a la Unión Europea, de ahí que comencemos en este momento a estudiar la vía del reasentamiento, una vía que, inicialmente al menos, parte con una doble limitación: por un lado, las estadísticas indican que solo el $1 \%$ de los refugiados son reasentados, luego hasta el momento se trata de una solución de carácter muy minoritario, puesto que solo está sirviendo para paliar la situación de un reducido número de personas necesitadas de protección; por otro lado, se trata de una solución indirecta, pues las personas que se benefician de ella son personas refugiadas en el territorio de terceros Estados en los que se encuentran en una situación de particular vulnerabilidad, razón por la que se hace necesario que se les reasiente en otro Estado. Pese a estas limitaciones que acabamos de señalar, el reasentamiento podría ser una herramienta magnífica si existiera un compromiso político por parte de los Estados de asumir su cuota de responsabilidad en el auxilio a los Estados que más flujos de refugiados acogen y que no cierran sus fronteras a cal y canto en la confianza de la puesta en práctica de este mecanismo. No obstante, se trata de una solución de último recurso, cuando otras soluciones duraderas - la repatriación voluntaria o la integración local - no constituyen una medida adecuada para la persona afectada por la medida.

Según la proyección sobre las necesidades anuales de reasentamiento realizada por ACNUR, en el año 2019 habrá en el mundo 1.400 .000 personas que necesitan ser reasentadas: el $42 \%$ de ellas son refugiados sirios - muchos de ellos presentes en Turquía - , a los que le siguen en mayor número congoleños $(11,64 \%)$ y sudaneses $(11,28 \%)^{52}$. Si bien las plazas

52 UNHCR Projected 2019 Global Reasettlement needs, 9-12. 
ofrecidas por los Estados de cara al reasentamiento fueron aumentando en el período 2012-2016, a escala global las cifras experimentaron un retroceso en el año 2017 con los consiguientes problemas en un contexto en el que 1.190.000 refugiados necesitaban ser reasentados. Y es que el número de personas que los Estados en su conjunto están dispuestos a reasentar es muy inferior al de las necesidades existentes. En el año 2017 -último año del que hay estadísticas completas - fueron reasentadas un total de 75.188 personas, mientras que entre enero y noviembre de 2018 han sido reasentadas $70.640^{53}$, unas cifras que, consideradas a nivel global y a la vista de las necesidades, son extremadamente pobres.

Pero, ¿qué es exactamente el reasentamiento? Tomando como referencia la definición ofrecida por ACNUR se entiende por reasentamiento «la selección y el traslado de refugiados desde el Estado en el cual han buscado protección hacia un tercer Estado que ha acordado admitirlos - como refugiados - con permiso de residencia permanente ${ }^{54}$. Por lo tanto, la determinación de la condición de refugiado bajo el mandato de ACNUR es una condición previa para la consideración del reasentamiento, a diferencia de lo que, como más adelante se analizará, parece proponer la Comisión Europea en su propuesta de Reglamento ${ }^{55}$. Es verdad, sin embargo, que junto a los refugiados que encajan plenamente en la definición de la Convención de 1951, ACNUR considera como susceptibles de reasentamiento personas que entrarían en la definición ampliada de refugiado, además de los apátridas, pero eso no quiere decir que todos los Estados acepten como elegibles para el reasentamiento a todos ellos, de ahí que ACNUR trate de acogerse, en la medida de lo posible, a la definición de la Convención ${ }^{56}$. Las razones por las que las personas pueden necesitar ser reasentadas pueden ser muy diversas: desde razones de seguridad, por ejemplo, derivadas de la extensión transfronteriza del conflicto del país de origen al Estado vecino o «la presencia de elementos del país perseguidor en el primer país de acogida»o

53 Para ver un desglose de los datos de 2017, ya cerrados, sobre países de procedencia, de acogida etc., UNHCR Projected 2019 Global Reasettlement needs, 69 y ss. Las cifras de 2018 figuran en la siguiente dirección de ACNUR: https://www.unhcr.org/resettlement-data.html.

${ }^{54}$ Manual de reasentamiento del ACNUR (Ginebra: ACNUR, Edición revisada 2011), 3. El estatuto que se les otorga les garantiza la protección contra la devolución y permite tanto a la persona refugiada reasentada como a su familia o personas dependientes que tengan acceso a derechos similares a aquellos que disfrutan los nacionales, pudiendo incluso convertirse en nacionales del país de reasentamiento mediante naturalización.

55 Esta cuestión se analiza en el epígrafe 2.4. Solo de manera excepcional ACNUR entiende que no es necesaria una calificación previa como refugiado para proceder al reasentamiento. Se trata del caso de las personas apátridas que no son refugiadas y de algunos familiares dependientes del refugiado, que tampoco sean refugiados. Ibid.pp. 79 y 81 .

56 Ibid., p. 89. 
la inexistencia de una mínimas condiciones de vida, derivadas de unos servicios sanitarios deficientes que no pueden atender determinadas enfermedades o la «crisis de refugiados de larga duración que agotan las capacidades del país de primera acogida ${ }^{57}$.

La práctica del reasentamiento viene realizándose por algunos miembros de la Unión Europea desde hace ya muchos años. Sin embargo, existen grandes divergencias entre los programas y prácticas de reasentamiento entre unos Estados y otros. Esas diferencias se plasman en elementos tales como «los criterios de selección, la duración de los procedimientos, los programas de orientación previos a la partida, los instrumentos de integración, el estatuto concedido a las personas admitidas, los permisos de residencia, así como el número de plazas de reasentamiento» ${ }^{58}$. Es por ello que resulta de máximo interés la adopción de una norma como la propuesta por la Comisión Europea, y a la que nos referiremos de forma inmediata, si consiguiera articular unas reglas comunes en materia de reasentamiento a escala de la UE.

El primer programa de reasentamiento en el marco de la Unión se activó a raíz de la recomendación de la Comisión de 8 de junio de 2015 de reasentar a 22.504 personas en un plazo de dos años ${ }^{59}$, y del acuerdo de 20 de julio de 2015 en el que los Estados Miembros (exceptuando Hungría), junto con - Islandia, Liechtenstein, Suiza y Noruega - acordaron reasentar a 22.504 personas que necesitaran claramente protección internacional en un plazo de 2 años $^{60}$. Los Estados asumieron sus compromisos voluntariamente, sirviendo como primera experiencia en reasentamiento para algunos de ellos. Aunque, las regiones que se consideraron como prioritarias fueron amplias, la mayoría de Estados participantes decidieron reasentar a

57 Rosario García Mahamut, «Reflexiones constitucionales sobre el reasentamiento de refugiados: el régimen jurídico del reasentamiento en Canadá y en España a la luz de la nueva ley de asilo y de la protección subsidiaria», UNED Revista de Derecho Político, N. $^{\circ} 8$ mayodiciembre (2010): 46.

$58 \mathrm{COM}(2016) 165$ final, 16 de marzo de 2016.

59 Recomendación (UE) 2015/914 de la Comisión de 8 de junio de 2015 sobre un programa europeo de reasentamiento. DOUE L 148/32. En la recomendación se fijaba un cupo para cada Estado al que se llegaba tomando en consideración los siguientes factores: tamaño de la población, como reflejo de la capacidad del Estado de acoger un determinado numero de refugiados; PIB total, expresión de la riqueza absoluta de un país, y por tanto como indicador de la capacidad de una economía de absorber e integrar a los refugiados; número medio de solicitudes de asilo espontáneas y número de refugiados reasentados por cada millón de habitantes durante el período 2010-2014, como reflejo de los esfuerzos realizados por los Estados en el pasado reciente, y, finalmente, tasa de desempleo (cifras de 2014), como indicador de la capacidad de absorción de los refugiados.

${ }^{60}$ Conclusiones del Consejo de la Unión Europea de 20 de julio de 2015 disponible en http://data.consilium.europa.eu/doc/document/ST-11130-2015-INIT/es/pdf. 
nacionales sirios procedentes de países vecinos, y como señaló la Comisión, aunque el programa fue «un hito importante en los esfuerzos de la UE en materia de reasentamiento no (creó) un marco claro de reasentamiento con normas y procedimientos comunes para los Estados participantes, sino que (fue) en gran medida una compilación de programas y procedimientos nacionales ${ }^{61}$. También la discutida Declaración UE-Turquía previó un mecanismo que teóricamente y al menos sobre el papel establecía un mecanismo para sustituir las llegadas irregulares desde Turquía a Grecia por el canal del reasentamiento desde Turquía a la UE, a través del mecanismo conocido como one in one out según el cual por cada sirio retornado a Turquía se llevaría a cabo el reasentamiento de un refugiado sirio desde Turquía a la Unión Europea $^{62}$. Todo ello permitió un cierto aumento del número de reasentamientos en el período 2015-2017, algo que tampoco era excesivamente difícil teniendo en cuenta las cifras de las que se partía. En 2014 fueron reasentadas 6.550 personas, 8.155 en 2015, para comenzar el ascenso en 2016 año en el que se reasentó a 14.200 personas $^{63}$. En mayo de 2018 y sobre la base de todos los programas de reasentamiento de la UE se habían reasentado a 32.207 personas $^{64}$. Pero los compromisos siguen siendo muy deficientes en relación a las necesidades existentes. En septiembre de 2017 la Comisión recomendaba reasentar a 50.000 personas más para octubre de 2019 , comprometiendo para ello la cantidad de 500 millones de euros procedentes del presupuesto de la $\mathrm{UE}^{65}$. El gobierno alemán asumió en febrero de 2018 el compromiso de reasentar a 10.200 personas $^{66}$, y a él se sumaron otros 20 Estados miembros, lo que ha permitido superar el compromiso de las 50.000 plazas $^{67}$. Es un esfuerzo significativo pero limitado en proporción al número de personas necesitadas de reasentamiento a escala global.

\section{La propuesta de Reglamento por el que se establece el Marco de Reasentamiento de la Unión}

No obstante todo lo anterior, la Comisión Europea ha sido consciente de la necesidad de pasar de regímenes ad hoc a un marco estable. Así, en

${ }^{61}$ COM (2016) 165 final, p. 19.

62 COM (2016) 197 final, p. 16.

${ }^{63}$ COM (2017) 558 final, p. 16.

${ }^{64}$ COM (2018) 301 final, p. 20.

65 COM (2018) 350 final, p. 21.

${ }^{66}$ Manual de reasentamiento del ACNUR, capítulo por países: Alemania, disponible en https://www.unhcr.org/5162b3bc9.html.

${ }^{67} \mathrm{COM}$ (2018) 301 final, p. 20. 
verano de 2016 y en el contexto del proceso de reforma del SECA, presentó la propuesta de Reglamento por el que se establece el Marco de reasentamiento de la Unión ${ }^{68}$, con el fin de crear un marco «más estructurado, armonizado y permanente» ${ }^{69}$. Nuestro propósito en las siguientes páginas consiste en analizar la propuesta inicial de la Comisión así como las posturas que en esta primera lectura están manteniendo el Parlamento - fundamentalmente la Comisión LIBE que es la que tiene atribuido el estudio del fondo, y en cuyo seno se aprobaron las propuestas de enmienda a la misma - y el Consejo, así como el resultado de las negociaciones interinstitucionales que han tenido lugar a lo largo de 2018, aun cuando la opacidad de los conocidos como trílogos dificultan conocer exactamente el punto en el que se encuentran las negociaciones ${ }^{70}$. Y es que si bien las negociaciones comenzaron en diciembre de 2017, a lo largo de 2018 y bajo la presidencia búlgara se celebraron varios diálogos tripartitos que permitieron avanzar, de ahí que el 13 de junio de 2018, el Parlamento y la Presidencia alcanzaran un acuerdo provisional sobre los principales elementos de la propuesta ${ }^{71}$. Sin embargo, presentado el texto al Comité de Representantes Permanentes no obtuvo el apoyo necesario y es en ese punto en el que nos encontramos, puesto que si bien la Presidencia del Consejo volvió a negociar algunos aspectos considerados como controvertidos por algunas delegaciones, lo cierto es que el Parlamento se remite al acuerdo al que se llegó el 13 de junio de $2018^{72}$.

${ }^{68} \operatorname{COM}(2016) 468$ final, 13 de julio de 2016 (2016/0225 (COD)). Algunos Estados apuestan por utilizar la Directiva como modo de creación del marco en cuestión. Nota de la Presidencia a las delegaciones, 8383/17, ASIM 38, RELEX 328, CODEC 622, 27 de abril de 2017, p. 14.

${ }^{69} \operatorname{COM}(2016) 468$ final, 13 de julio de 2016 (2016/0225 (COD)).

70 Sobre el desarrollo de las negociaciones y los trílogos, María Gómez Leal Pérez, «El procedimiento legislativo ordinario en la práctica: los acuerdos en primera lectura», Cuadernos Europeos de Deusto, 52 (2015): 101-118 disponible en http://dx.doi.org/10.18543/ced-52 -2015pp101-118.

${ }^{71}$ El acuerdo en cuestión se encuentra recogido en una nota de 19 de junio de 2018 dirigida por la Presidencia al Comité de Representantes Permanentes, pero que en el momento de cerrar el presente trabajo no es de acceso al público. Tras realizar la correspondiente solicitud, la Dirección General de Comunicación e Información ha entendido que su difusión afectaría al debate que está teniendo lugar. Ello nos ha impedido consultar el documento y conocer a través de la fuente principal y directa el acuerdo transaccional provisionalmente alcanzado.

72 Documento de la Presidencia al Consejo sobre el tema de 4 de octubre de 2018 11318/1/16 REV 1 ASILE 28 CODEC 1078, 11316/16 ASILE 26 CODEC 1076 + ADD 1, 11317/16 ASILE 27 CODEC 1077 + ADD 1 + ADD 2, 8765/1/16 REV 1 ASILE 13 EURODAC 3 ENFOPOL 132 CODEC 630, 12112/18 ASILE 59 CSC 253 CODEC 1459, 11313/16 ASIM 107 RELEX 650 COMIX 534 CODEC 1073. 


\subsection{Objeto del Reglamento}

El propósito de la Comisión al proponer el Reglamento se desprende de su exposición de motivos, de algunos de los considerandos y de los artículos 1 y 3 de la Propuesta. Es el artículo 1 de la propuesta el que advierte el objeto del mismo, esto es, establecer «un Marco de reasentamiento de la Unión para la admisión de nacionales de terceros países y apátridas en el territorio de los Estados miembros con el fin de concederles protección internacional», a lo que la Comisión LIBE propuso añadir «y brindarles una solución duradera ${ }^{73}$. Sin embargo, el Consejo, prácticamente desde el principio, propuso que el objeto del Reglamento no solo fuera reglamentar la admisión vía reasentamiento sino también a través de la admisión humanitaria, aún cuando existen en el seno del mismo opiniones divergentes entre sus miembros sobre la inclusión de la admisión humanitaria y el modo de hacerlo, pero eso es algo que el Parlamento Europeo parece haber aceptado en este momento.

El artículo 3 de la propuesta ilustra sobre el propósito de la misma: en primer lugar, pretende ofrecer un enfoque común - en aspectos tales como las condiciones de admisión, tipos de estatus ofrecidos en los estados miembros, procedimientos de toma de decisiones para su implementación, así como el apoyo financiero a los estados por sus esfuerzos - que reglamente la llegada legal y segura de nacionales de terceros Estados y apátridas que necesiten protección internacional al territorio de los Estados Miembros. De este modo, se reducirán las divergencias entre los procedimientos y prácticas nacionales, y, en consecuencia, el interés de los candidatos por acceder al territorio de un determinado Estado. En segundo lugar, el Reglamento pretende ayudar a la reducción del riesgo de entrada irregular a gran escala de todas esas personas en el territorio de los Estados miembros - riesgo para sus vidas y riesgo para la seguridad de los Estados por el descontrol que supone las llegadas espontáneas - y de la presión que ello supone sobre los sistemas de asilo nacionales. En tercer y último lugar, el Reglamento propuesto pretende colaborar con las iniciativas internacionales en materia de reasentamiento, de forma que la UE asuma su cuota de responsabilidad con los Estados particularmente afectados por los flujos de refugiados. Como se señala en la exposición de motivos, el Reglamento permitirá a la Unión «expresarse con una sola voz en los foros internacionales, asumir un

${ }^{73}$ Informe de la Comisión LIBE sobre la Propuesta de Reglamento por la que se establece un Marco de Reasentamiento de la Unión y se modifica el Reglamente (UE) n. ${ }^{\circ}$ 516/2014 del Parlamento Europeo y del Consejo, 19 de octubre de 2017, PE601.257v02-00 (en adelante Informe de la Comisión LIBE 2017 sobre la propuesta de Reglamento por el que se establece el Marco de Reasentamiento de la Unión), Enmienda 38. 
compromiso único de ayudar a las iniciativas globales de reasentamiento, y de este modo, dar visibilidad a sus esfuerzos con el fin de convencer a sus socios internacionales de que asuman su parte de responsabilidad» ${ }^{74}$.

Sin embargo, de la lectura de la exposición de motivos, de algunos de los considerandos - particularmente el 9 a 11, 16- y de algunas de las disposiciones contenidas en el Reglamento se desprende que la Comisión pretende utilizar el mecanismo del reasentamiento como una herramienta de control migratorio cuando, por ejemplo, explicita que podría utilizarse como mecanismo de «influencia en la política y el diálogo político con terceros países ${ }^{75}$, o cuando a la hora de fijar los criterios de determinación de las regiones o países desde los que se producirá el reasentamiento se incluye como factor a tener en cuenta el hecho de que el Estado coopere eficazmente con la Unión en materia migratoria - control de sus fronteras, readmisión de personas en situación irregular en la UE, entre otras cosas-. Aunque las propuestas de enmienda de la Comisión LIBE pretendieron suavizar en gran medida la pretensión de la Comisión Europea ${ }^{76}$, lo cierto es que el Consejo lo tiene muy claro y en este momento existe un riesgo real de que la iniciativa resulte adulterada respecto de lo que deberían ser los criterios para determinar si un determinado país debe ser auxiliado mediante el mecanismo del reasentamiento y la admisión humanitaria, pues se mantiene en este sentido el espíritu de la propuesta de la Comisión. Como ya se ha señalado desde fuentes autorizadas como la propia ACNUR ${ }^{77}$ y organizaciones como $\mathrm{ECRE}^{78}$, entre otras, el reasentamiento y también la admisión humanitaria debe responder a las necesidades de las personas en situación sumamente vulnerable y no convertirse en una herramienta de control migratorio.

\subsection{La definición de reasentamiento en la propuesta de Reglamento}

Según se desprende del artículo 1 de la Propuesta, el reasentamiento consiste en «la admisión de nacionales de terceros países y apátridas que necesiten protección internacional, desde un tercer país del cual o dentro del

74 COM (2016) 468 final, p. 3.

75 COM (2016) 468 final, p. 8.

76 Enmiendas 40-42 y 45-48, Informe de la Comisión LIBE 2017 sobre la propuesta de Reglamento por el que se establece el Marco de Reasentamiento de la Unión.

77 Proposal for a Regulation on the European Parliament and of the Council establishing a Union Resettlement Framework and amending Regulation (EU) n. ${ }^{\circ}$ 516/2014 of the European Parliament and the Council, UNHCR's Observations and Recommendations, disponible en https://www.refworld.org/docid/5890b1d74.html.

78 ECRE, Protection in Europe: safe and legal access channels. ECRE's vision on Europe's role in the global refugee protection regime: Policy paper 1 (2017): 18-26. 
cual han sido desplazados, al territorio de los Estados miembros con el fin de concederles dicha protección». Por un lado, se incluye a los desplazados internos como personas susceptibles de ser reasentadas, aunque ACNUR considera a estas personas como susceptibles de «asentamiento local» o de «asentamiento en otro lugar» ${ }^{79}$, no de reasentamiento en sentido estricto, algo en lo que coincide tanto el Parlamento como el Consejo, de ahí que los desplazados internos hayan quedado excluidos del ámbito de aplicación del Reglamento propuesto. Por otro lado, si bien la propuesta de la Comisión hace referencia al traslado a un Estado miembro «con el fin de concederles» («with a view to granting») protección internacional, la propuesta del Consejo es más acertada pues resulta más categórica al puntualizar que las personas a las que se traslada se les otorga protección internacional («who are granted international protection»). En conjunto, consideramos más acertada la definición propuesta por la Presidencia del Consejo cuando señala que «resettlement means the admission, following a referral from the UNHCR, of third country nationals or stateless persons in need of international protection as defined by article 2 (3) and (5) of Regulation (EU) XXX/XXX Qualification Regulation [...] who fall within at least one of the categories in article 5 (1) (b), and who are not excluded from resettlement in accordance with article 6 , from a third country to which [...] they have been forcibly displaced to the territory of the Member States [...] and who are granted international protection» ${ }^{80}$.

Como señalábamos, el Consejo ha propuesto que se incluya la admisión humanitaria dentro del Reglamento - y así parece haber sido aceptado en las negociaciones interinstitucionales, aun cuando el Parlamento rechazó inicialmente esta opción - y la define como la admisión de nacionales de terceros Estados o apátridas, que están al menos prima facie necesitados de protección internacional, desde un tercer Estado al cual han sido desplazados forzadamente al territorio de los Estados Miembros a quienes se les concede protección internacional ${ }^{81}$. Quizás no haya que contemplar esta inclusión necesariamente de forma negativa, pues probablemente permita un cauce flexible para responder a situaciones cambiantes, pero el peligro, quizás, provenga de una incorrecta utilización de la vía de la admisión hu-

79 Manual de reasentamiento de ACNUR..., 28, nota a pie 33. De conformidad con la fórmula propuesta por la Presidencia del Consejo los desplazados internos no serían beneficiarios del marco de reasentamiento y de admisión humanitaria de la Unión. Artículo 1 a) de la propuesta de la Presidencia, Nota de la Presidencia a las delegaciones, 8383/17, ASIM 38, RELEX 328, CODEC 622, 15.

80 Artículo 2. 1. de la Propuesta de la Presidencia, Nota de la Presidencia a las delegaciones, 8383/17, ASIM 38, RELEX 328, CODEC 622, 17.

${ }^{81}$ Artículo 2.2 de la Propuesta de la Presidencia, Nota de la Presidencia a las delegaciones, 8383/17, ASIM 38, RELEX 328, CODEC 622, 18. 
manitaria con la intención de reducir el número de personas admitidas bajo el paraguas del reasentamiento y limitar así los derechos y garantías de los que gozarían en el territorio del Estado miembro. El Consejo parece haber aceptado que el $60 \%$ de las plazas sean para reasentamiento (frente al $70 \%$ exigido por el Parlamento), pero ciertamente es un resultado poco reconfortante teniendo en cuenta que, como vamos a señalar a continuación, todo apunta a que será un porcentaje de una cuota total que no va a tener carácter vinculante para los Estados Miembros ${ }^{82}$.

\subsection{Planes anuales y programas específicos de reasentamiento}

Según advierte con claridad ACNUR, el reasentamiento no es una obligación legal de los Estados ni un derecho subjetivo de nadie ${ }^{83}$. Es una manifestación de solidaridad con los Estados que mayor afluencia de refugiados reciben y un ejercicio de responsabilidad compartida por todos. No sería por tanto, una obligación legal, pero sí una obligación moral, por lo que nada impide, sino todo lo contrario, que los Estados se comprometan a reasentar a una cuota del total de las personas respecto de la que es necesaria la adopción de esa medida conforme a la proyección de las necesidades que anualmente elabora la propia ACNUR. Y en este sentido, la Unión Europea puede, y a nuestro juicio debe, decidir la asunción de su propia cuota de responsabilidad respecto a las necesidades globales frente a la Comunidad Internacional.

La propuesta de Reglamento realizada por la Comisión diseña un sistema en el que se prevé la aprobación de Planes anuales (artículo 7) - si bien la Comisión LIBE y también el Consejo han propuesto que sean bianuales y ese parece ser el acuerdo entre este último y el Parlamento ${ }^{84}-$, por un lado,

${ }^{82}$ Nota de la Presidencia al Comité de Representantes permanentes, 4 de junio de 2018, ASIM 64, RELEX 493, CODEC 918: 3.

${ }^{83}$ Manual de reasentamiento del ACNUR..., 5. De hecho, el considerando 19 de la Propuesta de Reglamento dice explícitamente «No existe un derecho subjetivo a ser reasentado», si bien la Comisión LIBE ha propuesto la supresión del mismo. Informe de la Comisión LIBE 2017 sobre la propuesta de Reglamento por el que se establece el Marco de Reasentamiento de la Unión. La presidencia del Consejo sin embargo, aboga por mantener el considerando 19 en los mismos términos propuestos por la Comisión, y refuerza la idea de la no obligatoriedad de la admisión por parte de un Estado miembro o de la inexistencia de un derecho a ser admitidos en el territorio de los Estados miembros a favor de los nacionales de terceros estados o apátridas, Nota de la Presidencia a las delegaciones, 8383/17, ASIM 38, RELEX 328, CODEC 622, 15.

${ }^{84}$ Enmienda 61, Informe de la Comisión LIBE 2017 sobre la propuesta de Reglamento por el que se establece el Marco de Reasentamiento de la Unión, p. 39. Cfr. igualmente el Comunicado de prensa del Consejo, de 15 de noviembre de 2017 disponible en https://www. consilium .europa.eu/es/press/press-releases/2017/11/15/eu-resettlement-framework-councilready-to-start-negotiations/pdf. Artículo 7.1 de la propuesta de la Presidencia, Nota de la Presidencia a las delegaciones, 8383/17, ASIM 38, RELEX 328, CODEC 622, 33. 
y programas específicos de reasentamiento (artículo 8), por otro. Por lo que se refiere al Plan bianual se adoptará por el Consejo sobre la base de una propuesta de la Comisión - para lo cual, y aunque no se explicita en la disposición, debería tomar como referencia la proyección de las necesidades globales de reasentamiento de ACNUR y a la que antes nos referíamos - y lo hará el año anterior al que el mismo deba aplicarse. En el Plan se deberán explicitar, según se señala en el artículo 7, tres elementos básicos: cifra total de personas a reasentar, cuota que debe asumir cada Estado y país de procedencia de esas personas, aspectos todos ciertamente controvertidos.

En primer lugar y por lo que se refiere a la cifra global de personas a reasentar, el artículo 7 de la Propuesta de la Comisión señala que el Plan fijará el «número máximo» de personas que deben ser reasentadas —en la misma línea que el Consejo ${ }^{85}$-, de lo que se desprende que la cifra real podría ser inferior - incluso podría no reasentarse a nadie, puesto que aunque se construye la frase en términos imperativos, no se ha fijado un techo mínimo- - La Comisión de Asuntos Exteriores del Parlamento Europeo propuso la supresión del adjetivo «máximo», lo que supondría de este modo la aprobación de una cuota anual de personas que, una vez acordada, deberían ser reasentadas obligatoriamente ${ }^{86}$. Sin embargo, las propuestas de enmienda de la Comisión LIBE no han seguido exactamente este criterio sino que, en su lugar, ha planteado que el Plan recoja «un número establecido como objetivo de personas que deben ser reasentadas que refleje como mínimo el $20 \%$ de la proyección anual de las necesidades mundiales de reasentamiento». La referencia al establecimiento de un número determinado como objetivo sigue sin sugerir exactamente la idea de la obligatoriedad del reasentamiento de esa cifra, aún cuando a continuación se señale, en un alarde de compromiso, que esa cifra debería reflejar «como mínimo» el $20 \%$ de la proyección anual de las necesidades. A nuestro juicio, y en aras a que el reasentamiento funcione verdaderamente como una vía de acceso legal a la Unión Europea de personas necesitadas de protección internacional la redacción de este apartado debería señalar que el plan de reasentamiento

${ }^{85}$ La presidencia del Consejo sigue esa misma línea y se refiere al número máximo de personas que deben ser admitidas, pero añade «indicating, where relevant, what part of that number shall be dedicate to emergency admission», artículo 7.2.a) de la Propuesta de la Presidencia, Nota de la Presidencia a las delegaciones, 8383/17, ASIM 38, RELEX 328, CODEC 622, 34.

${ }^{86}$ Enmiendas 9 y 35, Opinión de la Comisión de Asuntos Exteriores para la Comisión LIBE sobre la propuesta de Reglamento por el que se establece un Marco de Reasentamiento de la Unión, 1 de junio de 2017, PE601-073v02-00 (en adelante Opinión de la Comisión de Asuntos Exteriores sobre la propuesta de Reglamento por el que se establece un Marco de Reasentamiento de la Unión). 
incluirá «el número de personas que deben ser reasentadas (en la línea de la propuesta de la Comisión de Asuntos Exteriores) que refleje como mínimo el $20 \%$ de la proyección anual de las necesidades mundiales de reasentamiento (en la línea de la propuesta de la Comisión LIBE). Sin embargo, las negociaciones entre Parlamento y Consejo no van en esa dirección, lo cual no hace sino incidir en la idea ya denunciada por algunos según la cual no se está concibiendo el reasentamiento ni la admisión humanitaria como verdaderos instrumentos para auxiliar a personas vulnerables y países colapsados por el flujo de refugiados que acogen, sino como una herramienta de control migratorio. El propio hecho de establecer cupos máximos y no mínimos ahondarían en esa idea, cuando en realidad estamos hablando de acoger a personas necesitadas de protección internacional en situaciones especialmente vulnerables.

En segundo lugar, la propuesta advierte que el plan concretará los detalles sobre la contribución de cada Estado al número total de personas que «deben ser reasentadas» (o «admitidas», según el Consejo, para incluir reasentamiento y admisión humanitaria). Para que no haya dudas, algunos Estados, como Hungría o Rumanía, han propuesto en el seno del Consejo que se haga referencia explícita a la voluntariedad de la contribución y yendo en esa misma dirección, la Presidencia ha propuesto que la contribución de cada Estado sea el reflejo de las indicaciones realizadas por cada uno de ellos en el Comité de Alto Nivel de reasentamiento ${ }^{87}$. Algunos Estados - como Bulgaria, Hungría o Eslovaquia - han propuesto incluso que se añada un inciso final al párrafo 2 del artículo 7 en el que se diga «The anual Union resettlement plan serves as a recommendation» ${ }^{88}$.

En tercer y último lugar, y por lo que se refiere al país de procedencia de las personas a reasentar, el Plan debe fijar las prioridades geográficas generales. Con ese fin, la propuesta de Reglamento fija en el artículo 4 los factores que se tomarán en consideración, algunos de los cuales son ciertamente

87 Artículo 7.2.b) de la Propuesta de la Presidencia, Nota de la Presidencia a las delegaciones, 8383/17, ASIM 38, RELEX 328, CODEC 622, 34. El Comité de Alto Nivel es un órgano consultivo en asuntos relacionados con el reasentamiento (y la admisión humanitaria, una vez incluida dentro del Reglamento), previsto en el artículo 13 de la Propuesta de la Comisión, compuesto por representantes (no se dice cuántos) del Parlamento Europeo, el Consejo, la Comisión (quien presidirá este órgano), el Alto Representante de la Unión para Asuntos Exteriores y Política de Seguridad y de los Estados miembros, que se reunirá al menos una vez al año o cuando sea necesario a invitación de la Comisión o a petición de un Estado miembro. La propuesta de la presidencia del Consejo amplía las funciones del Comité, que deberá invitar a los Estados miembros a participar en sus reuniones para que indiquen detalles de su participación y contribución al número máximo total de personas que serán admitidas en el marco del Plan y los Programas de Reasentamiento y admisión humanitaria. Nota de la Presidencia a las delegaciones, 8383/17, ASIM 38, RELEX 328, CODEC 622, 47.

88 Ibidem, nota a pie 109. 
criticables. En primer lugar, y como resulta totalmente lógico, se tendrá en cuenta el número de personas vulnerables que necesitan protección internacional en un determinado país, teniendo en cuenta las necesidades globales de reasentamiento proyectadas por el ACNUR. En segundo lugar, la propuesta se refiere con una redacción poco clara a «la complementariedad con la ayuda financiera y técnica ofrecida por terceros países hacia los cuales o dentro de los cuales se haya desplazado un gran número de personas» ${ }^{89}$. En tercer lugar, la propuesta considera que se ha de tener en cuenta el alcance y el contenido de los compromisos sobre reasentamiento contraídos por los terceros países ${ }^{90}$. Finalmente, nos referiremos a los dos últimos criterios que vienen a sugerir que la consideración de país o región prioritaria depende las buenas o malas relaciones que tengan con la Unión. En efecto, el que sería cuarto factor, previsto en el artículo 4, sería «las relaciones globales de la Unión con el tercer país o países desde los que produce el reasentamiento y con terceros países en general ${ }^{91}$. Y, en quinto y último lugar, y a nuestro juicio el más criticable de todos, haría depender la consideración como región o país de reasentamiento a la cooperación eficaz con la Unión en el ámbito de la migración y el asilo, algo por lo que parecía abogar también la Comisión de Asuntos Exteriores del Parlamento Europeo ${ }^{92}$ y el propio Consejo ${ }^{93}$,

${ }^{89}$ Se trata a nuestro juicio de un criterio que resulta un tanto confuso, y cuya redacción debería mejorarse, pues no termina de comprenderse del todo el sentido del mismo, tal y como puso de manifiesto Dinamarca en el seno del Consejo, Nota de la Presidencia a las delegaciones, 8383/17, ASIM 38, RELEX 328, CODEC 622, 20. En su lugar, podría acogerse la redacción propuesta por la Comisión LIBE que permite hacerse una idea de lo que en realidad se pretende: «garantizar la complementariedad con la ayuda financiera y técnica para mejorar la capacidad de acogida y las condiciones de protección ofrecidas a los terceros países hacia los cuales se hayan desplazado personas que necesitan protección internacional» (enmienda n. ${ }^{\circ}$ 46, Informe de la Comisión LIBE 2017 sobre la propuesta de Reglamento por el que se establece el Marco de Reasentamiento de la Unión).

${ }^{90}$ La presidencia del Consejo, sin embargo, propone la desaparición de este criterio, Nota de la Presidencia a las delegaciones, 8383/17, ASIM 38, RELEX 328, CODEC 622, 22.

${ }^{91}$ La Comisión de Asuntos Exteriores del Parlamento Europeo propuso en la enmienda 20 la supresión de este criterio, Opinión de la Comisión de Asuntos Exteriores sobre la propuesta de Reglamento por el que se establece un Marco de Reasentamiento de la Unión. Sin embargo, la Comisión LIBE lo mantuvo y en unos términos muy similares, también la Presidencia del Consejo (salvo que se propone suprimir la referencia a la relación «con terceros países en general», Nota de la Presidencia a las delegaciones, 8383/17, ASIM 38, RELEX 328, CODEC 622,15.

${ }^{92}$ La Comisión de Asuntos Exteriores del Parlamento Europeo se manifestó con claridad en la misma dirección hasta llegar a explicitar en la enmienda 4 al considerando 10 que «Es preciso, por tanto conceder prioridad a los países socios», Opinión de la Comisión de Asuntos Exteriores sobre la propuesta de Reglamento por el que se establece un Marco de Reasentamiento de la Unión.

${ }^{93}$ Nota de la Presidencia a las delegaciones, 8383/17, ASIM 38, RELEX 328, CODEC $622,22$. 
pero que en modo alguno compartimos pues, más en la línea de la Comisión LIBE, ACNUR, la OIM, Cáritas, Cruz Roja o Amnistía Internacional, consideramos que el reasentamiento debe seguir rigiéndose por el criterio de las necesidades de los refugiados más vulnerables y no por otro tipo de factores como la cooperación del tercer estado en materia de control de sus fronteras o de readmisión de personas que se encuentren irregularmente en la Unión.

No obstante todo lo anterior, el Plan se concretará a través de uno o varios programas específicos de reasentamiento (y admisión humanitaria) que serán adoptados por la Comisión ${ }^{94}$. Naturalmente estos programas deberán ser coherentes con el Plan propuesto y, como se señala en el artículo 8, cada uno de ellos incluirá al menos lo siguiente: A) Justificación detallada del programa. B) Número exacto de personas que deben ser admitidas del número máximo establecido en el plan, así como detalles sobre la participación de los Estados miembros en cada Programa. Sin embargo, dada la falta de voluntad política existente hasta el momento, la Presidencia del Consejo ha propuesto que la participación de cada Estado refleje las indicaciones que cada uno de ellos ha realizado en el seno del Comité de Alto Nivel, indicaciones que quedarían plasmadas en una cifra máxima y no en una cifra exacta, insistiendo, por tanto, en la idea de una participación voluntaria. C) Especificación de la regiones o terceros países desde los que se produce el reasentamiento (o la admisión humanitaria). D) Si fuera necesario, acuerdos sobre coordinación local y cooperación práctica con los Estados miembros. E) Descripción del grupo o grupos de nacionales de terceros países a los que se les aplicará el programa, para lo cual sería lógico que se tuviera en cuenta el informe de proyección de las necesidades mundiales de reasentamiento de $\mathrm{ACNUR}^{95}$. F) Especificación sobre si se aplica el procedimiento ordinario o el acelerado, concretando, cuando sea necesario, la forma en que se lleva a cabo la identificación y evaluación y el plazo para la toma de decisiones sobre el reasentamiento, si bien este elemento desaparecería en la propuesta de la Presidencia del Consejo pues, como veremos, desaparecería como tal la distinción entre procedimiento ordinario y acelerado. G) Fecha de entrada en vigor y duración.

${ }^{94}$ La Comisión LIBE ha propuesto una nueva redacción en virtud de la cual la adopción de programas específicos sería una facultad de la Comisión - frente a la redacción en términos imperativos de la propuesta inicial - , vehiculada a través de actos delegados y no de ejecución. Enmienda 69, Informe de la Comisión LIBE 2017 sobre la propuesta de Reglamento por el que se establece el Marco de Reasentamiento de la Unión, p. 41.

95 La Comisión LIBE ha propuesto que se explicite la referencia a la proyección de las necesidades globales de reasentamiento elaborada por ACNUR, que está ausente en la redacción original del artículo 8.2.e). Enmienda 73 Informe de la Comisión LIBE 2017 sobre la propuesta de Reglamento por el que se establece el Marco de Reasentamiento de la Unión, p. 43. 
En definitiva, de la redacción de los artículos 7 y 8 , tal y como parece que podrían resultar finalmente aprobados, se desprende que los Estados no se van a comprometer a admitir en sus territorios, vía reasentamiento o admisión humanitaria, a una cifra exacta de personas, circunstancia que nos sirve para tomar la medida del escasísimo compromiso de los Estados con quienes verdaderamente sufren la presión de la llegada masiva de refugiados y con los propios refugiados. Y en un signo más de actuación interesada, parece mantenerse como criterio para fijar los países o regiones preferentes el que cooperen eficazmente con la Unión en el ámbito de la migración y el asilo. Ambos elementos ensombrecen a nuestro juicio el texto del futuro Reglamento y no redundan en beneficio de la protección de los refugiados más vulnerables ${ }^{96}$.

\section{4. Ámbito subjetivo: criterios de admisibilidad e inadmisibilidad en programas de reasentamiento.}

Es el artículo 5 de la propuesta de la Comisión el que se refiere a los criterios de admisibilidad en los programas específicos de reasentamiento. Se trata de una lista ciertamente amplia que vamos a proceder a analizar. En primer lugar, el apartado a) hace referencia a refugiados, beneficiarios de la protección subsidiaria y desplazados internos. En relación a esta última categoría (la de los desplazados internos) parece existir un acuerdo entre la Comisión LIBE y el propio Consejo, pues, como ya se ha dicho, han propuesto su exclusión del ámbito subjetivo de aplicación del Reglamento, proponiendo en su caso la adopción de una norma específica al respecto ${ }^{97}$. Como una categoría aparte de personas que podrían beneficiarse del reasentamiento, el apartado b) del artículo 5 se refiere a nacionales de terceros Estados y apátridas que entren al menos en una de las categorías a las que nos vamos a referir a continuación: i) personas vulnerables por motivos diversos: mujeres y niñas en situación de riesgo, niños y adolescentes en idéntica situación, incluidos los menores extranjeros no acompañados, víctimas de la violencia o la tortura, personas con necesidad de protección física o jurídica, personas con necesidades médicas o discapacidades y, finalmente, personas con vulnerabilidad socioeconómica, una categoría novedosa y ciertamente amplia, pero cuya incorporación consideramos que podría ser positiva, a diferencia de la opinión de la Presidencia del Consejo

96 Nota de la Presidencia al Comité de Representantes permanentes, 2.

97 Opinión de la Comisión de Asuntos Exteriores sobre la propuesta de Reglamento por el que se establece un Marco de Reasentamiento de la Unión. Cfr. artículo 5.1.a) de la Propuesta de la Presidencia, Nota de la Presidencia a las delegaciones, 8383/17, ASIM 38, RELEX 328, CODEC 622, 15. 
que defiende su exclusión ${ }^{98}$. ii) Miembros de la familia de nacionales de terceros Estados, apátridas o de ciudadanos de la Unión que residen legalmente en un Estado miembro. Esta última categoría debería ser matizada, de tal forma que no se dé cabida por esta vía a aquellas personas que pudieran quedar amparadas por la Directiva 2003/86/CE del Consejo sobre el derecho a la reagrupación familiar, puesto que, de ser así no debería utilizarse la vía del reasentamiento «mermando» el número de plazas disponibles para otras personas necesitadas de protección ${ }^{99}$.

Aún cuando esta parece ser en esencia la línea que va a seguir la redacción tras las negociaciones interinstitucionales, a nuestro juicio era más acertada la redacción que propuso la Comisión LIBE y según la cual podrían ser candidatos al reasentamiento refugiados o personas con el estatuto de protección subsidiaria siempre y cuando entraran en alguna de las categorías que se enumeran en el apartado b) del artículo 5, esto es, personas vulnerables o familiares de personas residentes en la Unión, con los matices que ya se han señalado ${ }^{100}$. De otro modo, la redacción sugiere que cualquier refugiado o cualquier persona beneficiaria de la protección subsidiaria podría ser candidata al reasentamiento - sin exigir que se encuentre en una situación particular $-\mathrm{y}$, por otro lado, podrían ser reasentadas personas en situación vulnerable, pero que no tengan ni la condición de refugiado ni lo que podría ser la protección subsidiaria. Por ese motivo, como decíamos, consideramos más acertada la propuesta realizada por la Comisión LIBE, pues se ajusta mejor a los criterios establecidos por ACNUR.

El artículo 5 cierra la lista de los candidatos al reasentamiento y a la admisión humanitaria: por un lado, los nacionales de terceros países y apátridas que no entren en el ámbito de aplicación del artículo 1 D) de la Convención de Ginebra en lo relativo a la protección o asistencia de un órgano de Naciones Unidas distinto al ACNUR (c); y por otro, los nacionales de terceros países y apátridas a quienes las autoridades competentes del país en el que se encuentran no les hayan reconocido derechos y obligaciones inherentes a la posición de la nacionalidad de tal país o derechos y obligaciones equivalentes a ellos.

${ }^{98}$ La Presidencia del Consejo ha propuesto matices a este apartado, pero que no cambian en esencia el espíritu de la misma, Nota de la Presidencia a las delegaciones, 8383/17, ASIM 38, RELEX 328, CODEC 622, 24-25.

99 ECRE, «Untying the EU resettlement framework», Policy note (2016): 2. La Presidencia del Consejo ha propuesto incluir la cláusula «sin perjuicio» al inicio del apartado «Without prejudice to Council Directive 2003/86/EC on the right to family reunification, or to national law concerning family reunification...».

100 Enmienda 50, Informe de la Comisión LIBE 2017 sobre la propuesta de Reglamento por el que se establece el Marco de Reasentamiento de la Unión. 
Dado que, como ya se ha señalado la Presidencia del Consejo propuso que el Reglamento regulara también la admisión humanitaria, su propuesta prevé un nuevo párrafo dentro del artículo 5 según el cual «in case of humanitarian admission, third-country nationals or statelees persons shall be eligible for the Union Resettlement and Humanitarian Admission Scheme (...) where the eligibility criteria referred to in point (a) of paragraph 1 apply prima facie, and without having to fall within at least one of the categories refered in point (b) of paragraph $1{ }^{101}$.

Correlativamente, el artículo 6 de la propuesta presentada por la Comisión se refiere a las causas por las que las personas pueden quedar excluidas de los programas específicos de reasentamiento ${ }^{102}$ - causas comunes también a la admisión humanitaria, según la propuesta de la Presidencia del Consejo - y que deben ser examinadas antes de que un caso sea remitido para iniciar un procedimiento de reasentamiento, algunas de las cuales resultan a nuestro juicio completamente desproporcionadas.

En primer lugar, el artículo 6.1, apartado a) recoge las causas que operan como causas para la inadmisión en los programas de reasentamiento y que la Presidencia del Consejo propone mantener en unos términos muy similares: en primer lugar, la existencia de motivos razonables para considerar que una persona ha cometido un crimen contra la paz, un crimen de guerra o un crimen contra la humanidad, o bien que sea culpable de actos contrarios a las finalidades y a los principios de las Naciones Unidas, y, finalmente, el hecho de haber cometido un delito grave, circunstancias esta última que consideramos excesivamente amplia, por lo que consideramos acertada la propuesta que realizó la Comisión de Exteriores del Parlamento Europeo según la cual al menos debía tratarse de un delito grave «equivalente a una infracción punible con arreglo al Derecho penal de los Estados Miembros». La Comisión LIBE propuso simplemente que se apuntillara que el delito no debía ser político ${ }^{103}$. En todo caso, la redacción del apartado al que nos acabamos de referir es prácticamente idéntica a lo que señala ACNUR en su manual de reasentamiento como circunstancias que excluirían a una persona de ser reasentada.

101 Nota de la Presidencia a las delegaciones, 8383/17, ASIM 38, RELEX 328, CODEC $622,27$.

102 La Comisión LIBE y el propio Consejo parecen estar de acuerdo en referirse a causas de inadmisibilidad para participar en los programas de reasentamiento en lugar de causas de exclusión que podrían llevar a confundir con causas de exclusión de la condición de refugiado (enmienda 51, Informe de la Comisión LIBE 2017 sobre la propuesta de Reglamento por el que se establece el Marco de Reasentamiento de la Unión, p. 36).

103 Opinión de la Comisión de Asuntos Exteriores sobre la propuesta de Reglamento por el que se establece un Marco de Reasentamiento de la Unión, enmienda 30. Por otro lado, enmienda 54 de la Comisión LIBE, Informe de la Comisión LIBE 2017 sobre la propuesta de Reglamento por el que se establece el Marco de Reasentamiento de la Unión, p. 37. 
Además, según se señala en el apartado b) del artículo 6.1, serán inadmitidas en los programas específicos de reasentamiento las personas respecto de las que existan motivos «razonables» para considerar que suponen un peligro para «la sociedad, el orden público, la seguridad, la salud pública o las relaciones internacionales del estado miembro que examina el expediente». Como se puede apreciar se trata de un cajón de sastre que podría estirarse en exceso, pero cuyo mantenimiento la Presidencia del Consejo apoya, y que podría dejar desprotegidas a personas en situación de absoluta vulnerabilidad. En este sentido consideramos acertadas las propuestas de enmienda que realizó la Comisión LIBE en virtud de las cuales se exigiría la existencia de motivos «graves» (y no solo «razonables») para considerar que determinadas personas suponen «un peligro para la seguridad pública o nacional, o la salud pública, del Estado miembro», habiendo matizado igualmente que el peligro para la salud pública debe interpretarse como «una enfermedad con potencial epidémico en el sentido del Reglamento Sanitario Internacional de la Organización Mundial de la Salud» ${ }^{104}$.

No quedan ahí las causas de inadmisión sino que, según el apartado d), también opera como tal el hecho de haber permanecido o entrado irregularmente, o haber intentado hacerlo, en el territorio de los Estados miembros durante los cinco años anteriores al reasentamiento, causa que, muy oportunamente, tanto la Comisión LIBE como la Comisión de Exteriores del Parlamento Europeo ha propuesto que se suprima, pero cuyo mantenimiento defiende la Presidencia del Consejo ${ }^{105}$. A nuestro juicio, es muy probable que, precisamente, la situación de vulnerabilidad haya podido llevar a esas personas a huir en busca de protección y a intentar acceder de forma irregular al territorio de la Unión, lo que haría especialmente gravoso que tal circunstancia pudiera ser utilizada después como causa que les prive del proceso de reasentamiento. Por ese motivo esta causa de inadmisión debería

104 Enmiendas 9 y 55, Informe de la Comisión LIBE 2017 sobre la propuesta de Reglamento por el que se establece el Marco de Reasentamiento de la Unión. No obstante, aun cuando el reasentamiento no es un derecho de nadie ni una obligación del Estado, algunos incluyen como causas de exclusión por motivos de salud criterios que podrían ir contra el principio de no discriminación. Así, Estados Unidos - que es, sin embargo, uno de los Estados que más personas reasienta - incluye como causa de exclusión, por ejemplo, los trastornos mentales o físicos, el abuso actual o la adicción a las drogas. Section 101(a)(42) de la Immigration and Nationality Act (INA).

105 Enmienda 31, Opinión de la Comisión de Asuntos Exteriores sobre la propuesta de Reglamento por el que se establece un Marco de Reasentamiento de la Unión; Enmienda 57 Informe de la Comisión LIBE 2017 sobre la propuesta de Reglamento por el que se establece el Marco de Reasentamiento de la Unión. Manteniendo, sin embargo, la misma redacción que la propuesta original de la Comisión - salvo el hecho de que extiende la causa de exclusión por ese motivo a los programas de admisión humanitaria, cfr. Nota de la Presidencia a las delegaciones, 8383/17, ASIM 38, RELEX 328, CODEC 622, 29. 
desaparecer de la redacción definitiva, pues no viene sino a corroborar la idea de un cierta instrumentalización del Reglamento propuesto en aras al control migratorio.

Finalmente, el apartado f) del artículo 6.1, con una redacción a nuestro juicio un tanto confusa, señala que también quedarán excluidas de los programas específicos las personas a las que los Estados miembros hayan denegado el reasentamiento «con arreglo a este apartado» - se entiende que con arreglo al artículo 6.1- durante los cinco años anteriores al expediente, de lo que parece desprenderse que la denegación por un Estado puede permitir a otro excluir a esa persona del beneficio del reasentamiento, cuando podría darse la circunstancia de que la causa de exclusión no le fuera aplicable al segundo Estado ${ }^{106}$. Muy oportunamente la Comisión LIBE propuso su supresión ${ }^{107}$, pero el Consejo defiende su permanencia en unos términos prácticamente idénticos ${ }^{108}$.

Igualmente quedarán excluidas de los programas de reasentamiento las personas que ya hayan sido reasentadas por otro Estado miembro (artículo 6.1.f) - y añade el Consejo, siempre que a esa persona se le hubiera reconocido la protección internacional-, y las personas para las que se ha emitido una descripción en el Sistema de información de Schengen o en una base de datos nacional de un Estado miembro con el fin de denegar su entrada (artículo 6.1.c), reflejo, una vez más, del intento constante de utilizar el reasentamiento y admisión humanitaria como herramienta para llevar a cabo la política de control migratorio ${ }^{109}$.

Para concluir, el artículo 6, apartado 2) señala que la exclusión en el caso de los supuestos recogidos en los apartados a) y b), a los que nos hemos referido anteriormente, podrá operar cuando «a primera vista» concurra alguna de esas razones de exclusión. Con gran acierto, la Comisión de Exteriores del Parlamento Europeo y la Comisión LIBE propusieron la supresión de ese apartado, no así la Presidencia del Consejo ${ }^{110}$, que, además,

106 Pongamos por caso que un Estado miembro excluya a una persona del programa de reasentamiento por entender que pese a sus graves problemas de salud no tendría tratamiento adecuado, pero nada excluye que pueda disponer de ese tratamiento en otro Estado, y sin embargo, podría operar como causa de exclusión para este segundo. ECRE, «Untying the EU resettlement framework», op. cit., p. 3 .

107 Enmienda 59 Informe de la Comisión LIBE 2017 sobre la propuesta de Reglamento por el que se establece el Marco de Reasentamiento de la Unión.

108 Artículo 6.1 f) de la Propuesta de la Presidencia, Nota de la Presidencia a las delegaciones, 8383/17, ASIM 38, RELEX 328, CODEC 622, 30.

109 Artículo 6.1. e) de la Propuesta de la Presidencia, Nota de la Presidencia a las delegaciones, 8383/17, ASIM 38, RELEX 328, CODEC 622, 30.

110 Enmienda 33, Opinión de la Comisión de Asuntos Exteriores sobre la propuesta de Reglamento por el que se establece un Marco de Reasentamiento de la Unión. Enmienda 60 propuesta por la Comisión LIBE, Informe de la Comisión LIBE 2017 sobre la propuesta de 
ha propuesto la inclusión de dos nuevas causas de inadmisión. Por un lado, la de aquellas personas que durante los cinco años anteriores a la admisión no dieron o retiraron su consentimiento para ser admitidos en otro Estado miembro, algo que, a nuestro juicio, resulta cuando menos desproporcionado $^{111}$; por otro, aquellas personas respecto de las que haya elementos claros para afirmar que no existen perspectivas de integración en el Estado Miembro que examina el expediente, siempre que - añade a continuación, obligado a dar explicaciones - esa decisión se adopte sin discriminación por motivo alguno: sexo, raza, color y hasta más de una decena de moti$\operatorname{vos}^{112}$. El reasentamiento y la admisión humanitaria fueron concebidos para auxiliar a personas necesitadas de protección en situaciones de clara vulnerabilidad. Por lo tanto, resulta completamente improcedente excluir a persona alguna de tales programas incluso aunque se tenga la certeza de que la persona de que se trate no va a integrarse en el estado de destino, pues la situación de riesgo que viven no desaparece por tal motivo, de ahí que consideremos que estas últimas propuestas del Consejo deberían ser rechazadas de pleno por el Parlamento Europeo.

\subsection{Tipos de procedimiento: ordinario y acelerado}

La propuesta de Reglamento presentada por la Comisión prevé que los expedientes de reasentamiento se desarrollen conforme a dos tipos de procedimiento: uno ordinario y otro acelerado, regulados en los artículos 10 y 11, respectivamente. Sin embargo, como resultado de las negociaciones interinstitucionales todo apunta a que existirá un único procedimiento denominado procedimiento de admisión, regulado en el artículo $10^{113}$, pero veamos el punto desde el que se partía y a dónde se ha llegado hasta el momento.

\section{A) Procedimiento ordinario}

El procedimiento consta de varias etapas: identificación, registro, evaluación y decisión. En primer lugar, como en todo proceso de admisión - humanitaria o reasentamiento- es necesario identificar a los candidatos

Reglamento por el que se establece el Marco de Reasentamiento de la Unión. Cfr. igualmente Nota de la Presidencia a las delegaciones, 8383/17, ASIM 38, RELEX 328, CODEC 622, op. cit., p. 31 .

111 Artículo 6.2.b) de la Propuesta del Consejo, Nota de la Presidencia a las delegaciones, 8383/17, ASIM 38, RELEX 328, CODEC 622, 31.

112 Artículo 6.2.8bb) de la Propuesta del Consejo, Nota de la Presidencia a las delegaciones, 8383/17, ASIM 38, RELEX 328, CODEC 622, 32.

113 Artículo 10 de la Propuesta de la Presidencia, Nota de la Presidencia a las delegaciones, 8383/17, ASIM 38, RELEX 328, CODEC 622, 32. 
al mismo que, en todo caso, conservarán su derecho a aceptar o no la solución que se les proponga puesto que es una medida voluntaria que exige su consentimiento. Así lo reconoce el artículo 9 de la Propuesta de Reglamento advirtiendo que el mismo debe permanecer cuando se les indica exactamente a qué país van a ser trasladados. La propuesta de la Comisión no ha previsto consecuencia alguna derivada del rechazo de una propuesta concreta. Si bien la Comisión LIBE sugería ya la aplicación de alguna «sanción» en tal caso ${ }^{114}$, aunque sin especificar en qué consistiría, la Presidencia del Consejo ha propuesto que en el caso de no prestar o retirar el consentimiento, esa persona será considerada como inadmisible en los programas de reasentamiento por un período de cinco años ${ }^{115}$. Además, se ha dispuesto por parte del Consejo que se considerará una retirada implícita del consentimiento, con las consecuencias que ya se han señalado, la adopción de decisiones tales como la negativa a proporcionar datos o información esencial para conducir los procedimientos, o la negativa a atender la entrevista personal, salvo prueba en contrario de imposibilidad de hacerlo, algo que resulta a todas luces desproporcionado ${ }^{116}$.

En ese proceso de identificación de los candidatos a ser admitidos, el artículo 10 de la propuesta de la Comisión - presumiblemente aceptada por el Consejo ${ }^{117}$ - establece que los Estados miembros podrán dar preferencia, entre otras cosas, a quienes tengan vínculos familiares con nacionales de terceros Estados y apátridas o con ciudadanos de la Unión que residan legalmente en un Estado miembro, a personas con necesidades de protección o vulnerabilidades especiales, o a quienes tengan vínculos sociales o culturales «u otras características que puedan facilitar la integración en el Estado miembro participante» siempre que ello no conlleve discriminación de ningún tipo, aunque lo cierto es que la referencia a los vínculos sociales o culturales y la facilidad para la integración carece de justificación en un ámbito como el del reasentamiento y la admisión humanitaria en el que esencialmente nos estamos refiriendo a personas que necesitan ser trasladadas al territorio de otro Estado debido a la situación de vulnerabilidad en la que se encuentran, de ahí que este criterio debería suprimirse, como propuso la Comisión LIBE, que también propuso la desaparición del criterio de

114 Enmienda n. ${ }^{\circ} 76$ de la Comisión LIBE, Informe de la Comisión LIBE 2017 sobre la propuesta de Reglamento por el que se establece el Marco de Reasentamiento de la Unión.

115 Artículo 6.2.b) de la Propuesta de la Presidencia, Nota de la Presidencia a las delegaciones, 8383/17, ASIM 38, RELEX 328, CODEC 622, 31.

116 Artículo 6a) de la Propuesta de la Presidencia, Nota de la Presidencia a las delegaciones, 8383/17, ASIM 38, RELEX 328, CODEC 622, 33.

117 Artículo 10.1 de la Propuesta de la Presidencia, Nota de la Presidencia a las delegaciones, 8383/17, ASIM 38, RELEX 328, CODEC 622, 38. 
los vínculos familiares, e incluso el de las vulnerabilidades especiales, proponiendo en su lugar que los Estados miembros basen fundamentalmente su selección en la identificación y presentación de casos por el ACNUR ${ }^{118}$.

La propuesta planteada por la Comisión prevé como mera posibilidad que los Estados miembros solicitaran a ACNUR o a otros organismos internacionales que les remitieran los datos de las personas para los que esas entidades hubieran realizado una evaluación completa, sobre si entraban en el ámbito de aplicación del programa específico de reasentamiento de la Unión y si entraban en alguna de las categorías vulnerables que se consideran prioritaria ${ }^{119}$. Sin embargo, la Presidencia del Consejo ha propuesto la inclusión de dos nuevos apartados que abordarían el procedimiento de identificación diferenciado para reasentamiento y para admisión humanitaria. Por lo que se refiere al caso del reasentamiento, se exige muy oportunamente que los Estados miembros soliciten a ACNUR que les remita la identidad de nacionales de terceros Estados o apátridas en relación a los cuales ha evaluado completamente si: a) entran dentro del ámbito del Programa de Reasentamiento y admisión humanitaria de la Unión; b) entran dentro de una de las vulnerabilidades categorizadas en el artículo $5 \mathrm{y}$, c) si les califica como refugiados de conformidad con el artículo 1 del Convenio de 1951. Los Estados Miembros podrán solicitar que se tenga en cuenta los criterios de preferencia que se han señalado anteriormente. En el caso de la admisión humanitaria, los Estados miembros no están obligados pero podrán solicitar a ACNUR, a la Agencia Europea de Asilo o a otros organismos pertinentes que les remitan la identidad de nacionales de terceros Estados o apátridas en relación a los cuales ha evaluado si entran plenamente dentro del ámbito de aplicación del Programa. Igualmente podrán solicitar a ACNUR que evalúe si esas personas son consideradas refugiadas en el sentido del artículo 1 de la Convención de 1951. Finalmente podrán solicitar que se tenga en cuenta los criterios de preferencia anteriormente mencionados ${ }^{120}$. La intervención de ACNUR sería obligatoria en el proceso de reasentamiento y voluntaria en el proceso de admisión humanitaria.

En segundo lugar, tras la identificación de las personas para las que se propone su admisión comenzaría la fase de registro de toda una serie de información ${ }^{121}$, momento a partir del cual los Estados Miembros evaluarán

118 Enmiendas 79 a 79 de la Comisión LIBE, Informe de la Comisión LIBE 2017 sobre la propuesta de Reglamento por el que se establece el Marco de Reasentamiento de la Unión.

119 En particular el Reglamento se refiere a las categorías incluidas en el artículo 5, b) i).

120 Artículo 10.1a) y 10.1b) de la Propuesta de la Presidencia, Nota de la Presidencia a las delegaciones, 8383/17, ASIM 38, RELEX 328, CODEC 622, 38-39.

121 Entre la información solicitada se encuentran todos los datos personales, huellas dactilares de todos los dedos y una imagen facial de los candidatos a ser reasentados mayores de 6 años, tipo y número de cualquier documento de identidad o de viaje del que dispongan, fecha y lugar del registro y la autoridad que lo realiza (Propuesta de Reglamento, artículo 10.2). 
si esas personas cumplen con los criterios de admisibilidad del art. 5 o si quedan excluidas conforme a lo dispuesto en el art. 6, todo ello en el plazo más breve posible que no podría exceder de 8 meses $(6$ meses según la propuesta inicial de la Comisión LIBE), ampliable por 4 meses más (3 meses según proponía la Comisión LIBE) en casos particularmente complejos.

En el caso de que la decisión sea negativa, la propuesta de la Comisión - y en este sentido la propuesta de la Presidencia del Consejo es plenamente concordante - se limita a señalar que la persona en cuestión no será admitida, pero nada dice siquiera respecto a la notificación de la decisión, ni que deba estar motivada, ni mucho menos que la persona tenga derecho a asistencia legal o que la decisión sea susceptible de recurso ${ }^{122}$. Partiendo de la base de que son los Estados quienes seleccionan a las personas que van a ser reasentadas, el procedimiento aboca a una decisión absolutamente discrecional por parte del Estado, lo que hace del reasentamiento una medida útil pero extraordinariamente selectiva en la que la persona afectada no puede intervenir sino para aceptar o rechazar finalmente la oferta de reasentamiento que se le realice, en este último caso, además, con consecuencias negativas como las que ya se han señalado anteriormente, por lo que la capacidad de decidir se ve claramente condicionada ${ }^{123}$.

Por el contrario, si tras la identificación y el registro la decisión fuera la de proceder a la admisión de la persona, la propuesta de Reglamento de la Comisión - y en términos similares lo propuesto por la Presidencia del Consejo- prevé que el Estado miembro que lleva a cabo la evaluación le

122 Algunos miembros del Consejo como Francia y Holanda han propuesto que ACNUR notifique a la persona que se ha rechazado su admisión, algo que a nuestro juicio debería hacer el Estado miembro que haya rechazado la admisión de la persona de que se trate. En todo caso, hay que reconocer que tampoco el Manual de reasentamiento de ACNUR recoge nada respecto a la notificación, motivación, etc., pero como muy oportunamente ha señalado ECRE, «the refugee status determination procedures conducted by UNHCR as the Supervisory Authority over the Geneva Refugee Convention are essentially of a non-adversarial nature, contrary to State-led asylum procedures». Por lo tanto, ello no supone un problema cuando es ACNUR quien realiza el procedimiento de determinación de la condición de refugiado pero sí puede ser un problema cuando es un Estado quien realiza tal tarea. En todo caso, ACNUR está revisando sus procedimientos y ha previsto la asistencia de intérpretes y asesores legales, cfr. Procedural Standards for Refugee Status Determination under UNHCR's mandate, 2016, disponible en https://www.refworld.org/rsdproceduralstandards.html. La propuesta de enmienda n. $^{\circ} 89$ de la Comisión LIBE propone que se comuniquen los motivos por los que se toma la decisión de no completar el procedimiento en un dictamen motivado que será remitido al ACNUR, a los otros Estados miembros, a la Agencia de asilo de la Unión Europea y demás organizaciones que hayan presentado la solicitud para su seguimiento, pero nada se dice de la obligación de comunicación a la persona afectada.

123 Para ver una posición crítica con el sistema de toma de decisiones: Annelisa Lindsay, «Intensificación y selección: el poder en el régimen de reasentamiento de los refugiados», $R e$ vista Migraciones Forzadas, N. ${ }^{\circ} 54$ (2017): 11-14. 
concederá el estatuto de refugiado o el de protección subsidiaria - por lo tanto, no se garantiza el estatuto de refugiado-, según proceda, informándole de los derechos y obligaciones derivados del mismo que serán aplicables una vez que la persona se encuentre en el territorio de un Estado miembro. Igualmente, se les ofrecerá ayuda de cara a los preparativos del viaje, incluidos exámenes médicos, traslado gratuito al Estado Miembro de acogida, así como un programa de orientación previa a la partida que podría comprender cursos de idiomas, información sobre la realidad social, cultural y política del Estado miembro, derechos y obligaciones que conlleva su estatuto. sin que se haya indicado en la propuesta inicial por parte de la Comisión en qué plazo se debería producir el traslado. La propuesta de la Comisión no ha previsto el plazo máximo en el que la persona debería ser trasladada al Estado que ha llevado el expediente y ha decidido su admisión. La Presidencia del Consejo sí lo ha previsto pero proponiendo un plazo máximo de 12 meses desde la conclusión del expediente, tiempo que resulta a nuestro juicio completamente desmesurado, dadas las circunstancias en las que se encuentran quienes serían los beneficiarios, pues podrían transcurrir prácticamente dos años desde que se inicia el expediente hasta que se produce el traslado ${ }^{124}$.

\section{B) Procedimiento acelerado}

Como decíamos, la propuesta de la Comisión recogía un procedimiento acelerado que, en esencia, suponía la adopción de la decisión final en torno a un expediente en un plazo algo más breve pero excesivamente amplio - de 4 meses ampliable a 6 en supuestos especialmente complejos- en aquellos casos en que la propia Comisión hubiera previsto un procedimiento acelerado en el acto por el que se hubiera adoptado un programa específico de reasentamiento ${ }^{125}$. En una redacción absolutamente confusa parecía des-

124 Artículo 10.7. (aa) de la propuesta de la Presidencia del Consejo, Nota de la Presidencia a las delegaciones, 8383/17, ASIM 38, RELEX 328, CODEC 622, 44.

${ }^{125}$ El manual de reasentamiento de ACNUR recoge tres tipos de procedimientos: el normal, que tendrá una duración máxima de 12 semanas; el procedimiento urgente, que deberá concluir en 6 semanas, y, finalmente, el de emergencia, que exigirá que el reasentamiento se realice en el plazo de 7 días, Manual de Reasentamiento de ACNUR, op. cit., pp. 274 y ss. La Comisión LIBE ha propuesto suprimir la disposición relativa al procedimiento acelerado por otra en la que prevé un procedimiento de urgencia, no vinculado a ninguna región ni población particular, para casos en que la inminencia de los riesgos para la seguridad o la gravedad del estado de salud exijan una actuación inmediata. El procedimiento duraría dos semanas desde la presentación de la solicitud y garantizaría el traslado inmediato al Estado miembro que corresponda (enmienda 97, Informe de la Comisión LIBE 2017 sobre la propuesta de Reglamento por el que se establece el Marco de Reasentamiento de la Unión). 
prenderse que el resultado de un expediente tramitado por el procedimiento acelerado daría lugar a un único estatuto, el de la protección subsidiaria.

No obstante, la Presidencia del Consejo ha propuesto la supresión de este procedimiento, incluyendo en su lugar la noción de «admisión de emergencia» que consistiría en la admisión a través del reasentamiento o la admisión humanitaria de personas con necesidades físicas o jurídicas urgentes o con necesidades médicas inmediatas, «irrespective of a Union Resettlement and Humanitarian Admission Scheme in accordance with Article 8 , and irrespective of theoverall geographical priorities as referred to in paragraph 2 (c) of this Article» ${ }^{126}$.

\subsection{Financiación}

En último lugar vamos a referirnos a una cuestión de capital importancia como es la financiación del Marco de reasentamiento de la Unión. A ello se refiere el artículo 17 de la Propuesta de Reglamento en el que se prevé la modificación del Reglamento (UE) n. ${ }^{\circ} 516 / 2014$, por el que se crea el Fondo de Asilo, Migración e Integración. En este sentido, se propone que los Estados miembros que participan en el Reglamento reciban una cantidad a tanto alzado de 10.000 euros del presupuesto de la Unión por cada persona reasentada en virtud de un programa específico de reasentamiento de la UE. La propuesta de la Presidencia del Consejo supone una modificación importante a este respecto pues quedarían financiadas tanto las plazas propias de reasentamiento como las de admisión humanitaria con la misma cantidad de 10.000 euros. Y suplementariamente la propuesta de la Presidencia del Consejo ha propuesto que por cada persona reasentada de conformidad con los programas nacionales - que según se desprendía de la propuesta inicial de la Comisión y consta en la exposición de motivos, no recibirían apoyo financiero por parte de la Unión ${ }^{127}$ - el Estado miembro reciba, «within the limits of the resourses available, a lump sum of EUR $6.000 »$ siempre y cuando a la persona afectada se le haya reconocido protección internacional ${ }^{128}$. A nuestro juicio, ello podría ser valorado positivamente siempre y cuando esos programas nacionales supusieran una ampliación de las plazas disponibles respecto del compromiso adquirido por cada Estado en los planes y programas de reasentamiento de la Unión.

126 Artículo 2.3 y 7.2a) de la Propuesta de la Presidencia del Consejo, Nota de la Presidencia a las delegaciones, 8383/17, ASIM 38, RELEX 328, CODEC 622, 18.

$127 \operatorname{COM}(2016) 468$ final, op. cit., exposición de motivos, p. 17.

128 Artículo 17.3 de la Propuesta de la Presidencia del Consejo, Nota de la Presidencia a las delegaciones, 8383/17, ASIM 38, RELEX 328, CODEC 622, 50-51. 


\section{A modo de cierre}

Uno de los principales desafíos a los que debe hacer frente la Unión Europea en los próximos años es, desde luego, el derivado de los desplazamientos de importantes flujos de personas desde terceros países con destino a Europa, ya sea porque huyen de la persecución o de la guerra, porque huyen de la miseria más absoluta, o simplemente, porque, sin encontrarse en ninguna de esas situaciones tan extremas, desean una vida mejor y nuevas experiencias. El presente trabajo ha pretendido abordar algunas de las respuestas que desde el Derecho de la Unión se les puede ofrecer al primer grupo de personas, esto es, a las personas necesitadas de protección internacional, con el fin de permitir que quienes verdaderamente se encuentran en esa situación puedan acceder a suelo europeo de forma legal y segura, evitando un sufrimiento añadido difícil de explicar en una Europa asentada sobre valores como la dignidad y el respeto de los derechos humanos.

Para ello, es necesario un verdadero compromiso por parte de los Estados Miembros de la Unión, también de sus instituciones, en relación con las dos propuestas analizadas en el presente trabajo: la propuesta de articulación de un visado humanitario europeo y la propuesta para el establecimiento de un marco europeo de reasentamiento y admisión humanitaria. De nada sirven los lamentos cada vez que una nueva tragedia llama a nuestra puerta. Si de verdad se quieren evitar capítulos como los que todos tenemos en la memoria es necesario aprobar ambas herramientas jurídicas, y hacerlo en unos términos que supongan una garantía para las personas necesitadas de protección. Europa debe asumir su «cuota» de responsabilidad ante el grave problema que supone gestionar corrientes masivas de refugiados, corrientes masivas que están asumiendo otros y no nosotros, pese a que el discurso tóxico que está calando en una parte de la ciudadanía europea quiera hacernos creer una realidad distinta.

\section{Fuentes}

Abrisketa Uriarte, Joana. «La dimensión externa del derecho de la Unión Europea en materia de refugio y asilo: un examen desde la perspectiva del principio de non-refoulement», Revista de Derecho Comunitario Europeo, núm. 56 (2017): 119-158.

Bollo Arocena, M. ${ }^{\text {a }}$ Dolores. «Push back, expulsiones colectivas y principio de non refoulement. Algunas reflexiones a propósito de la sentencia dictada por la Gran Sala del Tribunal Europeo de Derechos Humanos en el caso Hirsi Jammaa y otros c. Italia (2012)», El Derecho Internacional en el mundo multipolar del siglo XXI: Obra Homenaje al Prof. Luis Ignacio Sánchez Rodríguez (Coord. S. Torres Bernárdez) (2013): 647-666. 
García Mahamut, Rosario. «Reflexiones constitucionales sobre el reasentamiento de refugiados: el régimen jurídico del reasentamiento en Canadá y en España a la luz de la nueva ley de asilo y de la protección subsidiaria», UNED Revista de Derecho Político, N. ${ }^{\circ} 78$ mayo-diciembre (2010): 43-93.

Gómez Leal Pérez, María. «El procedimiento legislativo ordinario en la práctica: los acuerdos en primera lectura», Cuadernos Europeos de Deusto, N. 52 (2015): 101-118.

González Vega, Javier Andrés. «¿Enterrando a Bankovic? La eficacia extraterritorial del Convenio Europeo a la luz de la sentencia del TEDH (Gran Sala), de 20 de noviembre de 2014 en el asunto Jaloud c. Países Bajos», Revista Española de Derecho Internacional, Vol. 67, N. ${ }^{\circ}$ 1, (2015): 312-317.

González Vega, Javier Andrés. «Mitos y mistificaciones: la Unión Europea y la protección internacional (a propósito de la crisis de los refugiados)», Revista de Derecho Comunitario Europeo, 56 (2017): 27-75.

Lindsay, Annelisa. «Intensificación y selección: el poder en el régimen de reasentamiento de los refugiados», Revista Migraciones Forzadas, N. 54 (2017): 11-14.

Morgades-Gil, Silvia. «Humanitarian visas and EU Law: do States have limits to their discretionary power to issue humanitarian visas?, European Papers, Vol. 2, N. 3 (2017): 1005-1016.

Sánchez Legido, Ángel. «El arriesgado acceso a la protección internacional en la Europa fortaleza: la batalla por el visado humanitario europeo», Revista de Derecho Comunitario Europeo, 57 (2017): 433-472.

Sánchez Legido, Ángel. Externalización de controles migratorios y derechos humanos (Por una reconstrucción del sistema de equilibrios y garantías en la Europa Fortaleza), Albacete (2019).

Wouters, Kees. International legal standards for the protection from refoulement: a legal analysis of the prohibitions on refoulement contained in the Refugee Convention, the European Convention on Human Rights, The International Covenant on Civil and Political Rights and the Convention against Torture, (2009).

Zoeteweij-Turhan, M.H. y Romano, A.«"X and X v. Belgium”: the need for EU Legislation on humanitarian visa», Sui-generis (2017): 68 y ss.

ACNUR, Manual de reasentamiento del ACNUR (Ginebra: ACNUR, Edición revisada 2011).

ECRE, «Untying the EU resettlement framework», Policy note (2016).

ECRE, Protection in Europe: safe and legal access channels. ECRE's visión on Europe's role in the global refugee protection regime: Policy paper 1 (2017).

ECRE's vision on Europe's role in the global refugee protection regime: Policy paper 1 (2017).

UNHCR Projected 2019 Global Reasettlement needs, Ginebra (25-26 junio 2017).

Propuesta de Reglamento del Parlamento Europeo y del Consejo relativo al Código sobre visados de la Unión (Código de visados) (refundición), 1 de abril de 2014, $\operatorname{COM(2014)~} 164$ final, 2014/0094 (COD).

Propuesta de Directiva del Parlamento Europeo y del Consejo por la que se aprueban normas para la acogida de los solicitantes de protección internacional 
(texto refundido), 13 de julio de 2016, COM (2016) 465 final, COM (2016) 467 final, 2016/0222 (COD).

Propuesta de Reglamento del Parlamento Europeo y del Consejo por el que se establece un procedimiento común en materia de protección internacional en la Unión y se deroga la Directiva 2013/32/UE, 13 de julio de 2016, COM (2016) 467 final, 2016/0224 (COD).

Documento de trabajo sobre visados humanitarios, Comisión LIBE, Ponente: Juan Fernando López Aguilar, 5 de abril de 2018 (PE619.272v02-00).

Informe sobre la propuesta de Reglamento del Parlamento Europeo y del Consejo relativo al Código sobre visados de la Unión (Código de visados) (versión refundida), Comisión de Libertades Civiles, Justicia y Asuntos de Interior. Ponente: Juan Fernando López Aguilar, 22 de abril de 2016 (Ref. A80145/2016).

Propuesta de Reglamento del Parlamento Europeo y del Consejo por el que se modifica el Reglamento (CE) n. ${ }^{\circ} 810 / 2009$ por el que se establece un Código comunitario sobre visados (Código de visados), 14 de marzo de 2018, COM (2018) 252 final, 2018/0061 (COD).

Informe sobre la propuesta de Reglamento del Parlamento Europeo y del Consejo por el que se modifica el Reglamento (CE) n. ${ }^{\circ} 810 / 2009$ por el que se establece un Código comunitario sobre visados (Código de visados), Comisión de Libertades Civiles, Justicia y Asuntos de Interior. Ponente: Juan Fernando López Aguilar, 6 de diciembre de 2018 (Ref. A8-0434/2018).

Enmiendas aprobadas por el Parlamento Europeo el 11 de diciembre de 2018 sobre la propuesta de Reglamento del Parlamento Europeo y del Consejo por el que se modifica el Reglamento (CE) n. ${ }^{\circ} 810 / 2009$ por el que se establece un Código comunitario sobre visados (Código de visados) COM (2018) 252-C80114/2018-2018/0061 (COD), P8_TA-PROV(2018)0495.

Humanitarian Visas. European Added Value Assessment accompanying the European Parliament's legislative own-initiative report (Rapporteur: Juan Fernando López Aguilar) (octubre 2018), disponible en https://publications. europa.eu/en/publication-detail/-/publication/a3b57ef6-d66d-11e8-942401 aa75ed71a1/language-en/format-PDF.

Sentencia del TJUE (Gran Sala) N.S y otros, C-411/10 y C-493/10, ECLI:EU:C:2011:865

Sentencia del TJUE (Gran Sala) X y X c. Bélgica, C-638/16 PPU, EU:C:2017:173. Conclusiones del abogado general Mengozzi en el asunto X y X c. Bélgica, C-638/16 PPU, EU:C:2017:93

\section{Sobre la autora}

María Dolores Bollo Arocena es profesora Titular de D. ${ }^{\circ}$ Internacional Público en la Universidad del País Vasco. Ha desarrollado una intensa actividad docente, investigadora y de gestión. Sus principales líneas de investigación son Derecho Internacional Penal, Derecho Internacional Humani- 
tario, Derecho Internacional de los Derechos Humanos, Inmigración, Asilo y Refugio. Ha participado en más de una docena de proyectos, obtenidos tanto en convocatorias autonómicas, nacionales como europeas. Es autora de dos monografías y de mas de una treintena trabajos científicos publicados tanto en revistas especializadas como en obras colectivas. La prof. Bollo cuenta con dos décadas de experiencia docente (Evaluación Docentiaz Excelente 2011-2017), habiendo impartido docencia y conferencias tanto en la UPV/EHU como en otras Universidades del Estado como la Autónoma de Madrid, Valencia, Castilla La Mancha o Islas Baleares, así como en universidades europeas como las de Siena, Catania o Lisboa. Igualmente, ha dedicado parte de su tiempo a la gestión: secretaria académica del Departamento de D. ${ }^{\circ}$ Internacional Público, Relaciones Internacionales e Historia del Derecho (2005-2010), Secretaria Académica de la Facultad de Derecho de San Sebastián (2010-2012) y Secretaria Académica de los Cursos de Derecho Internacional y Relaciones Internacionales de Vitoria Gasteiz (2009 hasta la actualidad)

\section{About the Author}

María Dolores Bollo Arocena is an Associate Professor of Public International Law at the University of the Basque Country. She has developed an intense teaching and research career and, also, has occupied management posts. Her main areas of research are International Criminal Law, International Humanitarian Law, International Human Rights Law, Immigration, Asylum and Refuge. She has participated in more than a dozen projects from regional, national and european calls. She is the author of two monographs and more than thirty scientific works published both in specialized journals and collective books. Professor Bollo has two decades of teaching experience (Docentiaz Excellent Evaluation 2011-2017). She has taught and gave lectures at the UPV/EHU and other Universities of the Spanish State such as the Universidad Autónoma of Madrid, Valencia, Castilla La Mancha or Islas Baleareas, and, also, in other European universities as Siena, Catania or Lisbon. By the same token, she has been in charge of management posts: Academic Secretary of the Department of Public International Law, International Relations and History of Law (2005-2010), Academic Secretary of the Law School of San Sebastián (2010-2012) and Academic Secretary of the Courses of International Law and International Relations of Vitoria-Gasteiz (2009 to the present) 


\section{Derechos de autor}

Los derechos de autor (para la distribución, comunicación pública, reproducción e inclusión en bases de datos de indexación y repositorios institucionales) de esta publicación (Cuadernos Europeos de Deusto, CED) pertenecen a la editorial Universidad de Deusto. El acceso al contenido digital de cualquier número de Cuadernos Europeos de Deusto es gratuito inmediatamente después de su publicación. Los trabajos podrán leerse, descargarse, copiar y difundir en cualquier medio sin fines comerciales y según lo previsto por la ley; sin la previa autorización de la Editorial (Universidad de Deusto) o el autor. Así mismo, los trabajos editados en CED pueden ser publicados con posterioridad en otros medios o revistas, siempre que el autor indique con claridad y en la primera nota a pie de página que el trabajo se publicó por primera vez en CED, con indicación del número, año, páginas y DOI (si procede). Cualquier otro uso de su contenido en cualquier medio o formato, ahora conocido o desarrollado en el futuro, requiere el permiso previo por escrito del titular de los derechos de autor.

\section{Copyright}

Copyright (for distribution, public communication, reproduction and inclusion in indexation databases and institutional repositories) of this publication (Cuadernos Europeos de Deusto, CED) belongs to the publisher University of Deusto. Access to the digital content of any Issue of Cuadernos Europeos de Deusto is free upon its publication. The content can be read, downloaded, copied, and distributed freely in any medium only for non-commercial purposes and in accordance with any applicable copyright legislation, without prior permission from the copyright holder (University of Deusto) or the author. Thus, the content of CED can be subsequently published in other media or journals, as long as the author clearly indicates in the first footnote that the work was published in CED for the first time, indicating the Issue number, year, pages, and DOI (if applicable). Any other use of its content in any medium or format, now known or developed in the future, requires prior written permission of the copyright holder. 